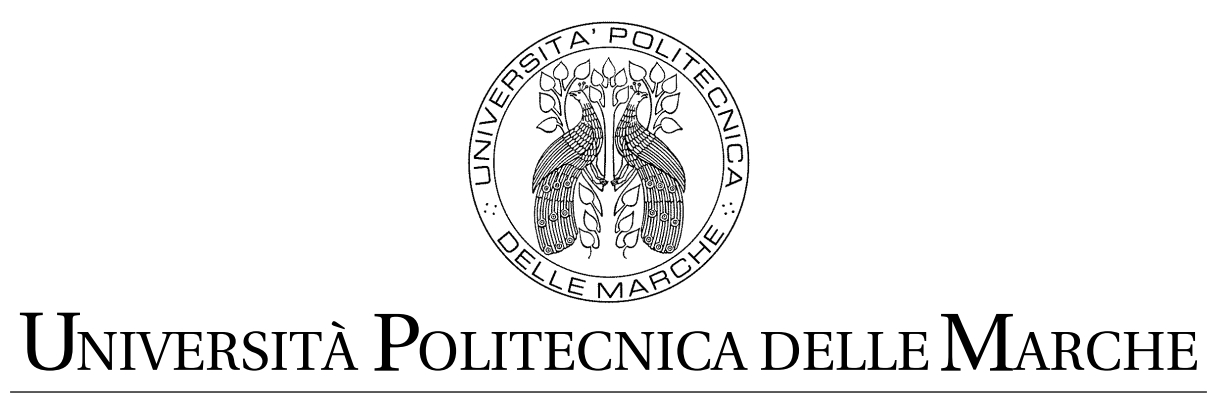

Dipartimento di Scienze Economiche e Sociali

THE FinANCIAL SUPPORT FOR LONG-TERM Elderly CARE AND Household SAVINGS BEHAVIOUR

Asako Ohinata And Matteo Picchio

QUADERNO DI RICERCA n. 411

ISSN: 2279-9575

September 2015 
Comitato scientifico:

Marco Gallegati

Stefano Staffolani

Alessandro Sterlacchini

Alberto Zazzaro

Collana curata da:

Massimo Tamberi 
JEL Class.: $\quad$ C21, D14, I18, J14

Keywords: Long-term elderly care; ageing; means tested financial support; wealth; saving; difference-in-differences

Indirizzo: Asako Ohinata. Corresponding author. Department of Economics, University of Leicester, Leicester, LE1 7RH, The United Kingdom; CentER, Tilburg University, The Netherlands. E-mail: ao160@le. ac.uk. Tel.: +44 1162522894. Matteo Picchio. Department of Economics and Social Sciences, Marche Polytechnic University, Piazzale Martelli 8, 60121 Ancona, Italy; CentER, Tilburg University, The Netherlands; Sherppa, Ghent University, Belgium; IZA, Bonn, Germany. E-mail: m.picchio@univpm.it. Tel.: +390712207176. 



\title{
The Financial Support for Long-Term Elderly Care and Household Savings Behaviour*
}

\author{
Asako Ohinata and Matteo Picchio
}

\section{Introduction}

The cost of long-term formal elderly care, offered to individuals aged 65 and above, is often covered entirely by each individual. Such costs pose significant financial uncertainties towards the elderly, since it is typically very difficult for individuals to predict the types and the duration of care in the future.

How to financially support the elderly and their families during the period of their long-term elderly care needs is a policy question that is often debated in many developed countries. Some countries, such as Germany and Japan, recently implemented long-term elderly healthcare insurance schemes, which partially subsidize the care cost. Other countries like the US and the UK often require substantial portion of the cost to be covered by individual households. Policy makers have the difficult task of striking a balance between ensuring comfort among the elderly by providing sufficient amount of affordable care and limiting the government expenditure. Moreover, the extent of the problem is likely to increase in the next decades due to the ageing population and the low fertility rates faced by many countries.

When designing a policy aimed at financially supporting the elderly with their care cost, it is imperative that one takes account of behavioural changes among the elderly and their families. One potential concern related to the introduction of a more generous system of formal elderly care is that households may reduce the amount of assets over their life-cycle, since they anticipate that they will rely more heavily on public funds.

${ }^{*}$ The authors would like to thank Effrosyni Adamopoulouthe, Aris Boukouras, Bruce Hollingsworth, Riccardo (Jack) Lucchetti, Ian Walker as well as seminar and conference participants in the European Society for Population Economics in Izmir, the Health Economists' Study Group in Lancaster, the iHEA conference in Milan. Asako Ohinata gratefully acknowledges financial support from the UK MRC research council. 
Several papers estimate structural life-cycle models incorporating uncertainties generated by medical expenses to understand the potential importance of precautionary saving behaviours in the US (Kotlikoff, 1989; Hubbard et al., 1994; Palumbo, 1999; De Nardi et al., 2010; Scholz et al., 2006; Kopecky and Koreshkova, 2014). Hubbard et al. (1994) and Palumbo (1999) report that taking account of medical expenditure uncertainties does not drastically impact the life-cycle saving profiles. Later studies, however, argue that the inclusion of this type of uncertainties in their models do improve their calibration results. De Nardi et al. (2010) suggest that the difference in the conclusions is likely to be due to improved access to more precise data on medical expenditures.

In addition, Gruber and Yelowitz (1999) and Maynard and Qiu (2009) investigate the impacts of the US Medicaid program on household wealth. Gruber and Yelowitz (1999) exploits the exogenous variation in Medicaid eligibility condition during the period 1984 1993 and find that Medicaid eligibility is negatively associated with household wealth. Maynard and Qiu (2009) find that the disincentive effect of Medicaid on household wealth is particularly strong among the middle net-worth households.

Evidence from outside of the US is virtually non-existent despite the fact that the non-US systems of long-term elderly care and financial public support often substantially differ from those in the US. Guariglia and Rossi (2004) does investigate the impact of private medical insurance on savings in the UK context. However, their focus is only on younger individuals aged between 25 and 65 and they do not specifically look at long-term care. ${ }^{1}$

Our paper therefore intends to present one of the first studies from outside of the US on the impact of financial support towards the long-term elderly care on the UK household savings behaviour. Moreover, since the aggregate private wealth might play a relevant role in the determination of capital accumulation and, thereby, in future economic growth (Solow, 1959; Romer, 1986; Lucas, 1988), it is of crucial importance to understand whether and to what extent the introduction of a more generous system of longterm elderly care could have had unintended consequences on household wealth over the life-cycle.

We exploit a 2002 Scottish reform, which started offering a part of the elderly care free of charge. Before this reform, Scotland and the rest of the UK shared the same public

\footnotetext{
${ }^{1}$ Potential effects arising from long-term care expenditure uncertainties are likely to be different from those of acute medical care expenditure uncertainties. This is because long-term elderly care can be offered by paid caretakers as well as informal family members and friends. In contrast, acute medical care must be offered by medical professionals, and therefore, do not have the close substitutes which would allow individuals to reduce their future expenditures.
} 
system for the long-term elderly care. Since this policy was introduced only in Scotland, UK households outside of Scotland can be used as a control group to disentangle the impact of such a Scottish reform on the wealth behaviour of the Scottish households from any other changes in assets induced by time effects common to all the UK regions. In addition, except for Kopecky and Koreshkova (2014), most existing studies focus either on the elderly population (Hubbard et al., 1994; Palumbo, 1999; De Nardi et al., 2010; Scholz et al., 2006) or pre-retirement individuals (Guariglia and Rossi, 2004). In contrast, our paper presents evidence across all post-educational age groups.

We find that the Scottish policy reform reduced the average household saving by about $£ 7,200$. In addition, the estimated negative effects are heterogeneous across the age of the head of household. These effects are particularly strong among the head of household aged between 40 and 60 . The largest effect is observed at age 49 with the reduction in the average household saving by about $£ 14,000$.

This article is set-up as follows. Section 2 provides background and institutional information on the 2002 Scottish reform. Section 3 discusses the theoretical predictions of the impact of the reform on savings. Section 4 presents the econometric model, the data, and the assumptions to identify the effects of the reform on household savings behaviour. Section 5 reports and comments on the estimation results. Section 6 describes a battery of robustness checks of our benchmark findings. Section 7 concludes.

\section{Background information}

\subsection{Historical background}

Individuals who have difficulties with daily activities receive personal care. Examples of personal care are bathing, toileting, assistance with preparation and eating food, and dressing. Personal care may be informally provided to the elderly by their family members. Paid personal care is also available from social workers administered by local authorities or privately hired caretakers. Paid personal care is referred to as "formal" care.

Prior to 2002, formal personal care cost in UK was paid almost entirely by individuals. $^{2}$ Such costs exposed each individual in need of long-term care to significant financial burden. In 2000, an average individual in England required 7.6 hours of personal care per week and the average hourly cost of personal care was approximately $£ 12$ (National

\footnotetext{
${ }^{2}$ Stringent means tested subsidies were offered to the elderly once their wealth fell below $£ 18,500$ (2001 rate).
} 
Statistics, 2002). Around 39 percent of households benefiting from home care received 6 or more visits and more than 5 hours of care per week. Half of these households required intensive care, defined as more than 10 contact hours and 6 or more visits during the week. In addition to charges for formal personal care, local authorities often charged for meals delivered to home or participating in day care sessions. The financial burden faced by the elderly, therefore, posed concerns among the UK policy makers (Netten et al., 2003).

The Royal Commission on Long Term Care for the Elderly was set up by the Labour government in December 1997 under the chairmanship of Sir Stewart Sutherland amid growing concerns regarding the financing of the elderly care. The Commission reported back to the UK Parliament in March 1999 (Sutherland report), recommending that for those aged 65 and above, formal personal care should be provided free of charge after rigorous need-based assessment conducted by local authorities. ${ }^{3}$

\subsection{Devolution and its consequences}

At the same time as the publication of the Sutherland report, the UK political system went through significant changes. More specifically, powers were transferred from Westminster to devolved governments in Scotland, Wales and the Northern Ireland. The devolved governments were introduced on 1st July 1999 in Scotland and Wales and on 2nd December 1999 in the Northern Ireland. England remained under the direct control of Westminster.

The establishment of devolved governments implied that each government acquired some scope to form its own health care policies although the differential degree of devolution meant that some had more autonomy from Westminster compared to the others. In response to the Sutherland report, Scotland welcomed the idea of state-funded personal care. The Scottish Executive set up the Care Development Group in January 2001, which was aimed at pursuing options on how to implement state-funded personal care and to evaluate the estimated cost of introducing such a policy. After several revisions, the Bill passed and received Royal Assent on 12 March 2002 to become the Community Care and Health (Scotland) Act 2002 (CCHA), which in turn was implemented on 1st July 2002. In contrast to Scotland, England, Wales and Northern Ireland did not follow the Commission's recommendation to make formal personal care free and continue to charge individuals for this type of care to this day.

The CCHA introduced the free formal personal care in Scotland but it distinguished care offered at home from the one received in residential care homes. If an individual

\footnotetext{
${ }^{3}$ The Commission however argued that the hotel costs and costs of meals on wheels or providing personal assistance with shopping should still be paid by individuals.
} 
received formal personal care at home, all personal care cost was covered as long as the local authority assessed the individual and approved the amount of care. ${ }^{4}$ Cost coverage for formal personal care provided in residential care homes was instead fixed at a flat rate. ${ }^{5}$

Table 1 highlights individuals' financial gains due to the reform by care setting and the region of residence. For each group, we calculate the maximum possible amount of weekly allowances given to individuals. The calculated amounts reflect other policy reforms that were implemented at the same time (see Appendix A for more information on these reforms). However, these reforms either affected all individuals across UK in a uniform manner or affected individuals heterogeneously but with very limited differences from the quantitative point of view. Therefore, our results in this paper are likely to reflect the isolated impact of the free personal care policy.

Table 1 indicates that the amount of financial gain experienced by the Scottish individuals receiving personal care at home stands out from the rest of the UK. In contrast, the modifications of the allowances for care received in residential care homes are only marginally heterogeneous across regions. However, the majority of individuals in UK receive care at home: in 2010-2011 only 1\% of the care recipients in England received care in residential care homes (English Longitudinal Study of Aging). Assuming that the UK individuals form expectations on their future care setting based on the current trend, the Scottish policy is likely to be relevant to the majority of the population. Based on the amount reported in Table 1, computing the difference between the variation in the allowances of care received at home in Scotland and the one in the rest of the UK yields $£ 145$ per week, ${ }^{6}$ which amounts to $£ 7,540$ per year.

Findings presented by Comas-Herrera and Wittenberg (2010) allow us to evaluate the potential expected lifetime gain received by Scottish individuals because of this policy. More specifically, they estimate the expected lifetime costs of local authority provided home care by employing the Personal Social Services Research Unit (PSSRU) macrosimulation model. By using a combination of information on the estimated duration of service receipt and the cost of these care services, they conclude that the expected lifetime costs of local authority provided personal care is $£ 3,150$ for males and $£ 5,650$ for females (at 2006-2007 prices). If households correctly evaluate the expected gain from the 2002

\footnotetext{
${ }^{4}$ On average, individuals received $£ 80$ per week for formal personal care received at home (National Statistics, 2012).

${ }^{5}$ In either case, individuals are still asked to pay other costs such as costs of cleaning, day care, laundry or meals on wheels.

${ }^{6}(£ 202.20-£ 53.55)-(£ 57.20-£ 53.55)=£ 145$.
} 
Table 1: Examples of weekly allowance calculations ( $£$ per week)

\begin{tabular}{|c|c|c|}
\hline & Before the reforms (2000 rate) & After the reforms (2003 rate) \\
\hline Care received in care homes & $£$ per week & $£$ per week \\
\hline England & 53.55 & 200.00 \\
\hline Wales & 53.55 & 176.86 \\
\hline Northern Ireland & 53.55 & 157.20 \\
\hline Scotland & 53.55 & 210.00 \\
\hline & Before the reforms (2000 rate) & After the reforms (2003 rate) \\
\hline Care received at home & $£$ per week & $£$ per week \\
\hline England & 53.55 & 57.20 \\
\hline Wales & 53.55 & 57.20 \\
\hline Northern Ireland & 53.55 & 57.20 \\
\hline Scotland & 53.55 & 202.20 \\
\hline \multicolumn{3}{|c|}{$\begin{array}{l}\text { Notes: This table illustrates how the maximum amounts of weekly allowances changed before } \\
\text { and after the reforms depending on where the elderly reside and where they receive care. The } \\
\text { pre-reform amounts are calculated using the } 2000 \text { rates whereas the } 2003 \text { rates are employed } \\
\text { for the calculations of the post-reform amounts. Since the formal personal care allowance in } \\
\text { Scotland for those receiving care at home is not fixed, we use the average amount provided to } \\
\text { the elderly, i.e. } £ 80 \text { (National Statistics, 2012). These calculations also incorporated the other } \\
\text { allowances such as the Attendance Allowances and the nursing care allowances to illustrate the } \\
\text { overall changes that individuals experienced over time. Details on these allowances are included } \\
\text { in the Appendix A. }\end{array}$} \\
\hline
\end{tabular}

Scottish reform, each household with a husband and his spouse would now require fewer savings in the amount of approximately $£ 8,800$.

\section{Theoretical predictions}

According to the life-cycle theory, agents plan their consumption and saving behaviour over their entire life-cycle on the basis of their wealth, i.e. the discounted sum of expected future income over life. In a permanent income hypothesis model, this implies that marginal utility of consumption is stable over time and is independent of age. However, when agents become aware of an unexpected shock on future income, they update their consumption and saving so as to be located again on an optimal consumption-savings path. As a result, when individuals experience an increase in income, they reduce their savings at all ages in order to smooth their consumption. Krueger and Perri (2010) shows that the magnitude of the reduction in savings depends on the length of the time interval between the knowledge of the shock and the effective future income variation. In particular, the model predicts that the farther away the income shock, the smaller the reduction in savings. Since the free personal care introduced in Scotland affected people who are aged 65 or older, we would expect the magnitude of the effect on household wealth to be increasing with age. 
Recent empirical papers have shown the importance of precautionary motives in determining households' propensity to save: i.e. the higher the uncertainty, the larger the propensity for saving (see, e.g., Kazarosian, 1997; Guariglia, 2001). The introduction of the free personal care in Scotland for the elderly reduced income uncertainty, but not with the same intensity for everybody. Those who are 65 or older at the time of the reform are likely to be subject to a smaller degree of uncertainty associated with their future income/expenditures, since they can better predict whether and to what extent they will need personal care in the near future. Since the reform might have generated a bigger reduction in income uncertainty for young and prime-aged households than for the elderly, we might expect a larger reduction in wealth for younger individuals.

Households might also be characterized by hyperbolic discount functions, i.e. by discount rates declining with the passage of time. Quasi-hyperbolic discount models predict low expected slopes of the consumption path and, therefore, a reduction of the intensity of the precautionary savings motive discussed above (Laibson, 1998; Frederick et al., 2002).

These three elements differentially affects households of various age groups. For young households, the predictions from these models are somehow mixed. These households have less incentives to smooth consumption and therefore reduce savings compared to older households whereas precautionary savings model predicts the reverse. In addition, the hyperbolic discount model suggests that these young households are less interested in positive income shocks in the very far future, and thus partially offset the reduction in savings predicted by the precautionary savings motive. Middle-aged households are instead exposed to stronger incentives to reduce their household savings compared to younger households, since both consumption smoothing and precautionary savings motives predict the reduction of savings: i.e. they are more strongly influenced by the consumption smoothing motive compared to younger households and they are exposed to greater uncertainties than near-retirement households. In addition, they are closer to retirement age and thus are less affected by the effect of the hyperbolic discounting. Finally, near-retirement households are under the influence of strong consumption smoothing motive, which generates the incentive to dissave, but the precautionary savings model suggests that these households are less likely to change their savings behaviour compared to other younger households.

In summary, theoretical models do not offer clearcut predictions on the overall effects across various age groups, and the identification of the policy effects is left to an empirical investigation. In what follows, we will analyse the effect of the reform of the personal care for the elderly on household wealth. Since we do not observe the flow, such as con- 
sumption or savings, we instead focus on a stock quantity made up of three components: amounts deposited in banks, values of houses, and mortgages.

\section{Estimation strategy, data, and identification}

\subsection{The econometric model}

In Subsection 2.2 we mentioned that individuals in Scotland receiving care at home are the major beneficiaries of the CCHA. The Scottish implementation of free formal personal care policy in the second half of 2002 stands out from the rest of the UK. In what follows, we will therefore evaluate the impact of the introduction of free formal personal care in Scotland on household wealth behaviour. Identification of the policy effect is attained by exploiting the fact that free personal care was introduced only for a specific group of individuals in the UK and that both the treated population (those in Scotland) and the untreated population (those in the rest of UK) are observed before and after the reform.

Comparing household wealth in Scotland before and after 2002 is problematic since there may have been many economic influences other than the policy introduction that affected household wealth over time. Similarly, a simple difference between the average household wealth in Scotland and in the rest of the UK after 2002 also pauses a problem because there might be fundamental differences in the household wealth behaviour between the two regions. As a result, we employ a difference-in-differences (DD) estimator and estimate changes in the differences of the household wealth between Scotland and the rest of the UK before and after the reform.

Our empirical evaluation will be in a repeated cross sections framework. We specify the following model for wealth $y$ of household $i$ living in region $r$ in tax year $t$

$$
y_{i r t}=\mathbf{x}_{i r t}^{\prime} \boldsymbol{\beta}+\boldsymbol{\gamma}_{r}+\phi_{t}+\delta_{D D} I_{r t}+\varepsilon_{i r t},
$$

where:

- $\mathbf{x}_{i r t}$ is the $K \times 1$ vector of relevant household characteristics and $\boldsymbol{\beta}$ is the conformable vector of coefficients. The regressors in $\mathbf{x}_{\text {irt }}$ are a flexible function of age, gender, race, and marital status of the head of household, the education of the head of household and of the spouse (if present), the presence of kids of different ages, and a set of controls for time-varying regional heterogeneity and regional specific trends, like the regional unemployment rate, per capita gross value added, and per 
capita gross disposable income.

- $\gamma_{r}$ is a set of regional fixed effects (regional dummies).

- $\phi_{t}$ is a set of time fixed effects (tax year dummies).

- $I_{r t}$ is the regressor of interest. It is an indicator variable equal to 1 if the household resides in Scotland after the reform, i.e. after March 2002. We chose this cut off month since the Scottish bill introducing free personal care for the elderly passed on 12 March 2002. The corresponding parameter $\delta_{D D}$ is the effect of the introduction of free personal care in Scotland on wealth.

- $\varepsilon_{\text {irt }}$ is the error term at household level.

The parameters of Eq. (1) are estimated using Ordinary Least Squares (OLS). Standard errors are corrected to take into account the correlation of shocks within each region. More specifically, given $R$ the number of regions, we will compute $\sqrt{R /(R-1)}$ clustered robust standard errors and $t_{R-1}$ critical values as suggested in Brewer et al. (2013).

Following the discussion in Section 3, we are interested in estimating potentially heterogeneous effects of the policy across age of the head of household. We therefore estimate a more general version of Eq. (1).

$$
y_{i r t}=\mathbf{x}_{i r t}^{\prime} \boldsymbol{\beta}+\boldsymbol{\gamma}_{r}\left(a g e_{i r t}\right)+\phi_{t}\left(a g e_{i r t}\right)+\boldsymbol{\delta}_{D D}\left(a g e_{i r t}\right) I_{r t}+\varepsilon_{i r t},
$$

where:

- $\gamma_{r}\left(a g e_{i r t}\right)$ is the regional fixed effects are interacted with a flexible function of age, so that each region could potentially be characterized by its own flexible relationship between age and wealth.

- $\phi_{t}\left(a g e_{i r t}\right)$ is the time fixed effects are interacted with a flexible function of age, so that the flexible effects of age on wealth is allowed to potentially vary each year.

- $\boldsymbol{\delta}_{D D}\left(a g e_{i r t}\right)$ is the effect of the reform which is allowed to flexibly vary across age.

To reduce the number of parameters to be estimated and to avoid model over-specification, we constrain $\gamma_{r}\left(a g e_{i r t}\right)$ and $\phi_{t}\left(a g e_{i r t}\right)$ so that the age profile of wealth is: i) common across all the untreated regions (all the regions but Scotland); ii) constant over time in the years before and in the years after the reform, but allowed to suddenly vary when the 
reform is introduced in 2002. We tried different flexible age functions. We will present estimation results coming from a fractional polynomial specification of the age functions, with powers $\{-2,-1,-0.5,0,1,2,3\}{ }^{7}$ and piecewise constant functions by grouping age in intervals of two years. ${ }^{8}$ Both specifications, as well as other flexible attempts, return very similar estimation results.

\subsection{Data, sample, and variable definition}

This study employs the repeated cross sectional dataset of the UK Family Resources Survey (FRS). FRS was collected by the Department for Work and Pension on a yearly basis since 1992. Every year approximately 24,000 private households and 45,000 individuals are interviewed and information is collected at the household, benefit unit, and individual levels. Our analysis is carried out at the household level. The final sample covers the years from 1999 until 2007. We analyse from the year 1999, the year in which the Scottish government established its devolved government. Moreover, data was only included until the year 2007 so as to avoid the 2008 financial crisis, which may confound the effect of the policy introduction. FRS only collected information on households in Northern Ireland from the 2002/2003 survey. We, therefore, exclude Northern Ireland from our sample. Finally, we further restrict the sample to those whose head of household is 25 or above. This is to minimize the chance of including households whose main earners are still in education. Our initial sample size was 309,336 households. After applying these selection criteria and dropping observations with missing information on the variables used in the econometric analysis, we are left with a sample made up of 158,562 observations.

The dependent variable in our model is household wealth, defined as the the sum at household level of bank deposits, bonds/gilts, and housing values, minus any remaining mortgages and debts. In the original dataset we do not observe the actual value of the house in each observation year. Instead, we only observe purchased house prices. We estimate housing values starting from purchased house prices using the following two step procedure. First, we separately regress purchased house prices on various housing characteristics for each governmental region. The characteristics of houses used as regressors are: number of floors, number of bedrooms, year in which the house was purchased, coun-

\footnotetext{
${ }^{7}$ According to the leave-one-out cross validation (LOOCV) statistic, this fractional polynomial specification of the age functions is to be preferred to more parsimonious alternatives. We computed the LOOCV statistic as $\frac{1}{N} \sum_{i=1}^{N}\left(\frac{\widehat{\varepsilon}_{i}}{1-h_{i}}\right)^{2}$, where $\widehat{\varepsilon}_{i}$ is the OLS residual and $h_{i}$ is the leverage.

${ }^{8}$ Conditional on grouping age in equally spaced bins, grouping age in intervals of two years returns the best LOOCV statistic.
} 
cil tax bands, and whether the house is detached, semi-detached, or a flat. Since the UK tax system could influence the housing prices, we also control for tax year dummy variables. ${ }^{9}$ Second, we use the resulting estimated parameters to predict the housing values at the year of the observation in the FRS. ${ }^{10}$

Table 2 presents descriptive analysis of household wealth before and after March 2002 for Scotland and the rest of the UK. The household wealth is divided into three components: amounts deposited in banks, values of houses and mortgages. The first two columns show the average values for Scottish households before and after the policy introduction. The third column indicates the difference in the average values for those households between the two periods. The latter four columns indicate similar statistics for England and Wales. The last column presents the double differenced values, illustrating the changes in differences between the Scotland versus England and Wales over time. Three points emerging from Table 2 are worthy of mention. First, Scottish households on average hold fewer savings compared to those in England and Wales. This is true regardless of looking at the pre- or post-reform periods. Second, all the households in the UK seem to hold the majority of their assets in houses and not in cash deposited in banks. Third, the last column indicates that the overall wealth for Scottish households declined over time compared to those in England and Wales. The difference-in-differences of the average wealth is, unconditional on household, regional and time heterogeneity, significant and equal to $£-6,561.86$. The household bank deposits, however, is not the major contributor of the observed reduction of the average saving overtime, but it is the house values and the mortgages/debts left to be paid.

Table 3 reports descriptive statistics of the variables used in the econometric analysis. Overall, the household wealth amount to $£ 49,958$ on average, mainly made up by the house values, net of the mortgages/debts left to pay. The bank deposits (including bonds and gilts) are on average equal to $£ 1,678$ only. The mean age of the head of household is 46.8 years; the median is 44 years, which we report given that the age variable is censored at 80 , causing the mean to be downward biased. The head of household is female in $41.6 \%$ of the cases and non-white in $10.2 \%$. The households residing in Scotland are $15.6 \%$ of the sample, followed by the South East with $12.9 \%$, London with $11.4 \%$, and North West and Merseyside with $11.3 \%$; $48.8 \%$ of the households reside in the remaining seven regions. Most of the households, 54.6\%, are couples (either married or cohabiting). The regional unemployment rate was about $5.3 \%$ on average over the time window 1999-

\footnotetext{
${ }^{9}$ The UK tax year starts in April.

${ }^{10}$ The estimation results of the equation for the purchased house prices are not reported in the text for the sake of brevity. They are however available upon request from the authors.
} 


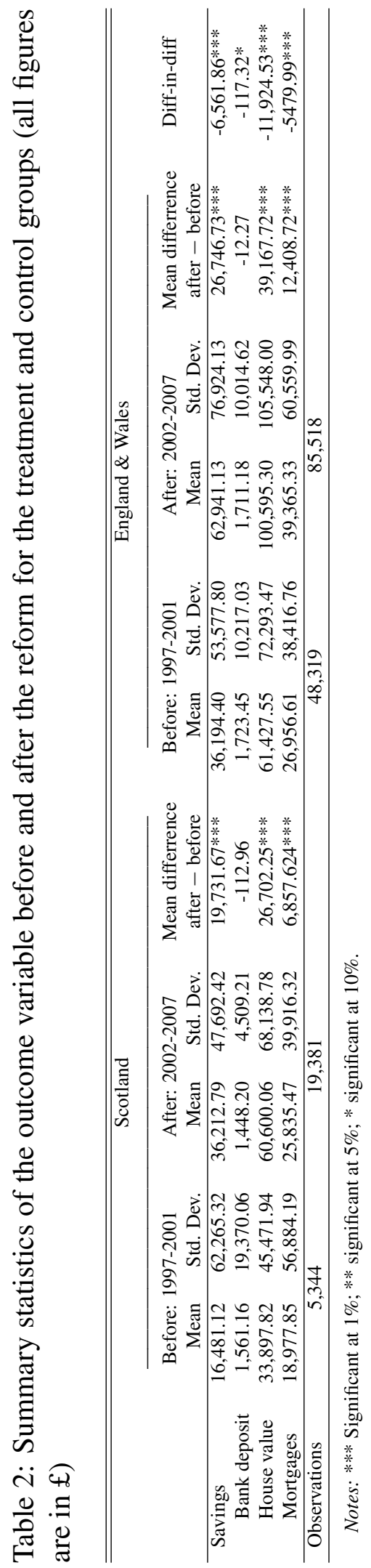


2007 and the per capita gross disposable income and gross value added were $£ 12,455$ and $£ 16,779$, respectively.

Table 3: Summary statistics of the variables used in the econometric analysis

\begin{tabular}{|c|c|c|c|c|}
\hline & Mean & Std. Dev. & Minimum & Maximum \\
\hline Household wealth $(£)$ & $49,957.70$ & $68,441.94$ & $-3,687,234.00$ & $2,494,868.00$ \\
\hline Bank deposits (f) & $1,677.72$ & $10,051.73$ & 0.00 & $2,500,270.00$ \\
\hline House value ( $(\mathfrak{)})$ & $81,523.09$ & $93,205.80$ & 0.00 & $816,750.30$ \\
\hline Mortgages (£) & $33,243.12$ & $52,700.48$ & $0.003,723,679.00$ & \\
\hline $\mathrm{Age}^{\S}$ & 46.774 & 15.078 & 25.000 & 80.000 \\
\hline Female & 0.416 & 0.493 & 0.000 & 1.000 \\
\hline Non-white & 0.102 & 0.303 & 0.000 & 1.000 \\
\hline \multicolumn{5}{|l|}{ Region of residence } \\
\hline North-East & 0.047 & 0.212 & 0.000 & 1.000 \\
\hline North West and Merseyside & 0.113 & 0.317 & 0.000 & 1.000 \\
\hline Yorkshire and the Humber & 0.084 & 0.277 & 0.000 & 1.000 \\
\hline East Midlands & 0.068 & 0.252 & 0.000 & 1.000 \\
\hline West Midlands & 0.082 & 0.275 & 0.000 & 1.000 \\
\hline Eastern & 0.087 & 0.281 & 0.000 & 1.000 \\
\hline London & 0.114 & 0.318 & 0.000 & 1.000 \\
\hline South East & 0.129 & 0.335 & 0.000 & 1.000 \\
\hline South West & 0.074 & 0.262 & 0.000 & 1.000 \\
\hline Wales & 0.045 & 0.208 & 0.000 & 1.000 \\
\hline Scotland & 0.156 & 0.363 & 0.000 & 1.000 \\
\hline \multicolumn{5}{|l|}{ Civil status } \\
\hline Married & 0.455 & 0.498 & 0.000 & 1.000 \\
\hline Couple & 0.091 & 0.287 & 0.000 & 1.000 \\
\hline Single & 0.197 & 0.398 & 0.000 & 1.000 \\
\hline Widowed & 0.089 & 0.284 & 0.000 & 1.000 \\
\hline Separated & 0.049 & 0.216 & 0.000 & 1.000 \\
\hline Divorced & 0.119 & 0.324 & 0.000 & 1.000 \\
\hline \multicolumn{5}{|l|}{ Education:age left } \\
\hline $0-12$ & 0.004 & 0.062 & 0.000 & 1.000 \\
\hline $13-15$ & 0.300 & 0.458 & 0.000 & 1.000 \\
\hline $16-18$ & 0.497 & 0.500 & 0.000 & 1.000 \\
\hline $19-21$ & 0.096 & 0.294 & 0.000 & 1.000 \\
\hline $22-23$ & 0.066 & 0.248 & 0.000 & 1.000 \\
\hline $24-27$ & 0.030 & 0.170 & 0.000 & 1.000 \\
\hline 28 and above & 0.007 & 0.083 & 0.000 & 1.000 \\
\hline \multicolumn{5}{|l|}{ Education of the spouse: age left } \\
\hline $0-12$ & 0.001 & 0.038 & 0.000 & 1.000 \\
\hline $13-15$ & 0.111 & 0.315 & 0.000 & 1.000 \\
\hline $16-18$ & 0.245 & 0.430 & 0.000 & 1.000 \\
\hline $19-21$ & 0.049 & 0.215 & 0.000 & 1.000 \\
\hline $22-23$ & 0.030 & 0.171 & 0.000 & 1.000 \\
\hline $24-27$ & 0.011 & 0.103 & 0.000 & 1.000 \\
\hline 28 and above & 0.002 & 0.049 & 0.000 & 1.000 \\
\hline Presence of kids $<5$ years & 0.180 & 0.474 & 0.000 & 4.000 \\
\hline \multirow[t]{2}{*}{ Presence of kids $[5,11)$ years } & 0.253 & 0.576 & 0.000 & 5.000 \\
\hline & \multicolumn{4}{|c|}{ Continued on next page } \\
\hline
\end{tabular}


Table 3 - continued from previous page

\begin{tabular}{|c|c|c|c|c|}
\hline & Mean & Std. Dev. & Minimum & Maximum \\
\hline Presence of kids $[11,15)$ years & 0.212 & 0.522 & 0.000 & 4.000 \\
\hline Regional unemployment rate by gender (\%) & 5.276 & 1.415 & 2.900 & 10.500 \\
\hline Per capita regional gross value added $(\mathfrak{£})$ & $16,778.99$ & $4,830.55$ & $10,047.00$ & $34,828.00$ \\
\hline Per capita regional gross disposable income $(\mathfrak{E})$ & $12,455.42$ & $1,910.89$ & $8,910.00$ & $18,386.00$ \\
\hline Variation of per capita regional gross value added (£) & 760.44 & 376.03 & 125.00 & $2,613.00$ \\
\hline Variation of per capita regional gross disposable income $(\mathfrak{E})$ & 457.49 & 173.11 & 88.00 & 932.00 \\
\hline \multicolumn{5}{|l|}{ Tax year } \\
\hline 1999 & 0.115 & 0.319 & 0.000 & 1.000 \\
\hline 2000 & 0.108 & 0.311 & 0.000 & 1.000 \\
\hline 2001 & 0.115 & 0.319 & 0.000 & 1.000 \\
\hline 2002 & 0.121 & 0.327 & 0.000 & 1.000 \\
\hline 2003 & 0.118 & 0.322 & 0.000 & 1.000 \\
\hline 2004 & 0.113 & 0.316 & 0.000 & 1.000 \\
\hline 2005 & 0.111 & 0.315 & 0.000 & 1.000 \\
\hline 2006 & 0.102 & 0.302 & 0.000 & 1.000 \\
\hline 2007 & 0.097 & 0.296 & 0.000 & 1.000 \\
\hline Observations & \multicolumn{4}{|c|}{158,562} \\
\hline
\end{tabular}

$\S$ Age is censored at 80 years of age.

\subsection{Identification assumptions}

The identification of the policy effects through a DD approach is based on some underlying assumptions.

Assumption 1 (Parallel trend assumption): Conditional on $\left(\mathrm{x}_{i r t}, \gamma_{r}, \phi_{t}\right)$, households residing in Scotland experience similar trends in wealth behaviour as those in the rest of the UK in the absence of the 2002 reform.

We test the validity of Assumption 1 by comparing the trends in household wealth of England-Wales and Scotland. The left hand side of Figure 1 shows the trends of wealth in Scotland and England-Wales, whereas the right hand side displays the difference in the wealth between the two groups. If the saving behaviour in Scotland followed the same trends as those in England and Wales, the two saving lines on the left hand side of Figure 1 should be parallel and the curve in the right hand side should be horizontal before 2002. Eyeballing the graph, they roughly look parallel to each other. We conduct a formal test by first regressing household wealth on a full set of tax year dummies interacted to an indicator for Scotland and by testing the joint equality of these interactions before 2002 . The coefficients of these interactions represent the distance between the Scottish trend and the one of England and Wales. Testing their joint equality before 2002, we evaluate whether the distance between the two trends is constant from 1999 until 2001, i.e. that the two trends are parallel before the reform. Our results indicate that the null hypothesis 
cannot be rejected and thus the parallel trend assumption seems to be fulfilled ( $p$-value $=0.155) .^{11}$

Figure 1: The parallel trend assumption
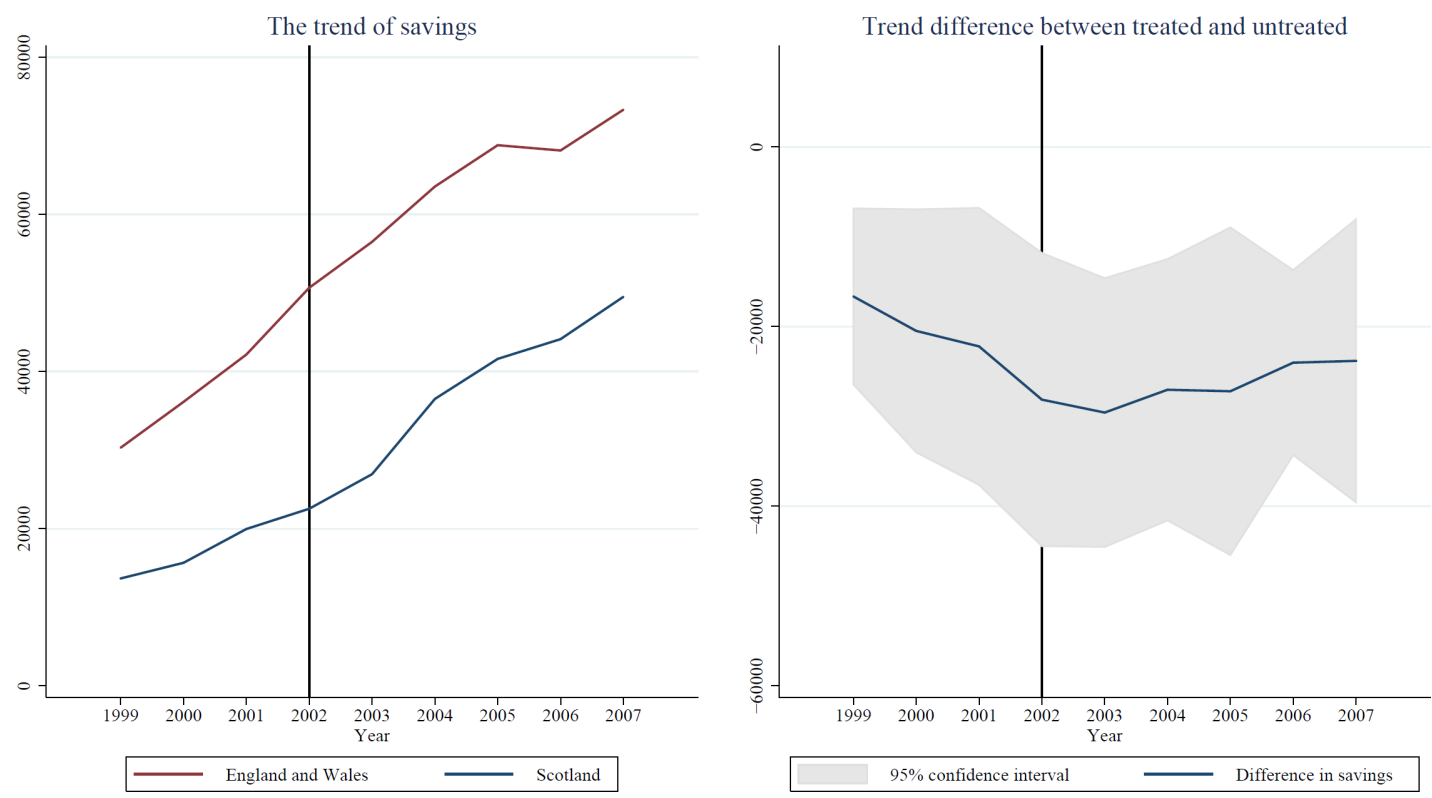

Notes: We formally test whether the distance between the wealth of Scotland and England and Wales was constant between 1999 and 2001 , i.e. before the policy reform of the elderly care system. We cannot reject the null hypothesis $(p$-value $=0.155)$ of parallel trends before the reform.

Assumption 2 (Exogeneity of the intervention): Conditional on $\left(\mathbf{x}_{i r t}, \gamma_{r}, \phi_{t}\right)$, the Scottish free personal care reform is exogenous and not motivated by demand for personal care in Scotland but rather politically determined.

If Scotland implemented the 2002 free personal care policy in response to an increasingly stronger demand for formal personal care, we would have an endogeneity problem, as the policy variable after 2002 would capture the effect on wealth of both the reform and of the differential trends in the demand for personal care. This would then translate into potentially diverging trends in wealth between the two groups of regions not because of the policy introduction but rather due to differential underlying demand for formal

\footnotetext{
${ }^{11}$ We also run a similar test by regressing household wealth on all the covariates in Eq. 1. The test of joint equality of coefficients of the interactions between the Scotland indicator and the tax year dummies before 2002 cannot reject the null hypothesis $(p$-value $=0.183)$.
} 
elderly care. Figure 2 presents the trends of the demand of personal care in England and Scotland. ${ }^{12}$ The left and right panels of Figure 2 illustrate the trends of, respectively, 1-5 hours and 6 or more hours of personal care usage per week. Although the aggregated data used to plot these graphs does not allow us to formally test whether these lines are parallel to each other, the plotted trends suggest that these two regions did not experience differential trends.

Figure 2: The trends in the demand for personal care in Scotland and England
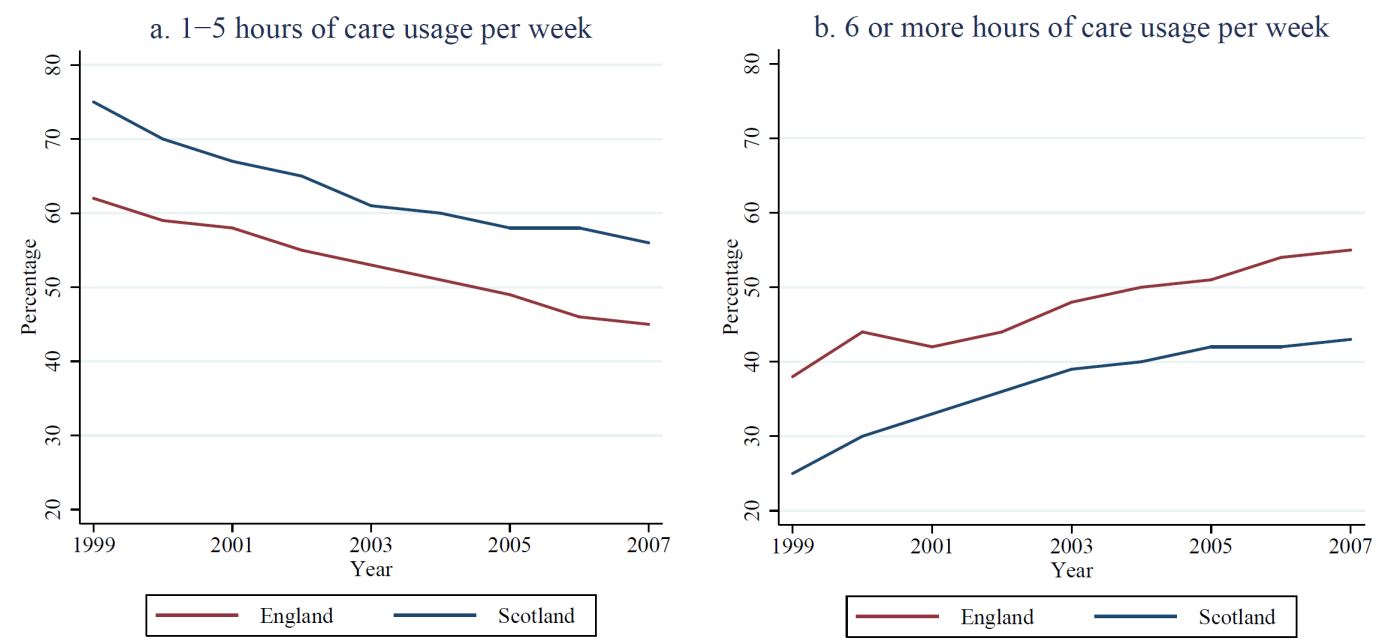

Notes: We plot the trends in the demand for personal care in Scotland and England. The left-hand side figure shows the trends in the fraction of households using 1-5 hours of care at home per week. The right-hand side figure reports the trends for the fraction of households using 6 or more hours of care per week. Statistics for Wales is not available, since data is not in the same format as those in England and Scotland. However, given that the population of Wales represents less than 5\% of the UK population, the exclusion of Wales should not affect much the calculated trends.

Sources: Community Care Statistics 1999, 2000, 2001, 2002, 2003, 2004, 2005, 2006, and 2007. Home Care Services, Scotland 2000, 2004, 2007, and Social Care Statistics 2014.

Assumption 3 (Stable sample composition): Conditional on $\left(\mathrm{x}_{i r t}, \boldsymbol{\gamma}_{r}, \boldsymbol{\phi}_{t}\right)$, the composition of the treated and control groups is assumed to be stable before and after the policy.

Assumption 3 requires that the composition of the households residing in Scotland, England, and Wales be stable over the observation years, conditional on observed covariates. Our findings would be biased if, for example, those who anticipate greater needs for formal personal care and those without much savings move to Scotland from England or

\footnotetext{
${ }^{12}$ Statistics for Wales is not available, since data is not in the same format as those in England and Scotland.
} 
Wales due to the 2002 policy. Using the 1999-2007 British Household Panel Survey (BHPS), we analyse if individuals' moving behaviour changed before and after the policy introduction. ${ }^{13}$ Table 4 presents estimates from a linear probability model, where the dependent variable equals to 1 if individuals moved to Scotland from England or Wales. It is regressed on a dummy indicator noting if each individual moved in Scotland after 2002 and 0 othewise. In all cases but for age groups 45-54 and 65-85, we find that the policy introduction did not result in significant effect of individuals moving into Scotland. However, even for the two age groups 45-54 and 65-85, we conclude that we do not find any evidence to suggest that individuals moved into Scotland in response to the policy introduction. This is because (1) the signs are negative suggesting that individuals are less likely to move into Scotland after the policy introduction (2) the sizes of these effects are very small.

Table 4: Probit regression estimates to test whether individuals moved to Scotland in response to the introduction of the free formal personal care policy

\begin{tabular}{|c|c|c|c|c|c|}
\hline Dependent variable: 1 if moved to Scotland & Age 25-34 & Age 35-44 & Age 45-54 & Age 55-64 & Age $65-85$ \\
\hline 1 if observed after 2002 & $\begin{array}{c}0.0005 \\
(0.0004)\end{array}$ & $\begin{array}{c}0.0002 \\
(0.0003)\end{array}$ & $\begin{array}{c}-0.0004 * \\
(0.0002)\end{array}$ & $\begin{array}{l}-0.0003 \\
(0.0003)\end{array}$ & $\begin{array}{c}-0.0004^{*} \\
(0.003)\end{array}$ \\
\hline Observations & 26,797 & 29,709 & 25,110 & 21,436 & 26,268 \\
\hline
\end{tabular}

Assumption 4 (No anticipation): Scottish households were not able to anticipate the introduction of the personal care reform.

The Scottish government's decision to take up the recommendation received wide media coverage as early as January 2002. For example, BBC announced that the free personal care for Scotland would be introduced in July of the same year on 15 January 2002. Similarly, the Guardian published an article after one of the Bills passed in the Scottish Parliament (Inman, 2002). As a result of this wide media coverage and considering that we have information on wealth on the basis of tax years (which start in April), households could have anticipated the introduction of the policy. The Scottish individuals might then have faced the incentives to alter their consumption and savings decisions before

\footnotetext{
${ }^{13}$ The BHPS is a UK longitudinal survey, which began in 1991. It collects approximately 5,500 households and 10,300 individuals drawn from 250 areas of the UK. It records detailed information on whether and when individuals moved to different parts of the UK.
} 
April 2012. If this were the case, the estimated effects would be biased towards zero. In order to test for this identification assumption, we run a robustness analysis in Section 6 by eliminating observations in tax years 2001 and 2002. As we will see, we find that removing these two years from our sample does little to our findings.

\section{Estimation results}

\subsection{Baseline parameter estimates}

The OLS baseline estimation results of the parameters characterizing Eq. (1) are reported in Table 5 and Figure 3. The former reports the point estimates of the coefficients of all regressors, but those of the age function. The latter focuses on the estimated relation between the age of the head of household and household wealth: since this relation is flexibly modelled, multiple parameters determine the effect of age on wealth and therefore we prefer to show it graphically. In both Table 5 and Figure 3, we report two sets of estimation results. The difference lies in the specification of the age function. As mentioned in Subsection 4.1, we use a fractional polynomial specification of the age function, with powers $\{-2,-1,-0.5,0,1,2,3\}$, as well as a piecewise constant age function by grouping age in intervals of two years. The results reported in Table 5 and Figure 3 show that all the estimated parameters are not sensitive to the chosen parametrization of the age function.

The estimated coefficient of $I_{r t}$ in Table 5, i.e. the indicator for living in Scotland after the reform, suggests that the introduction of the 2002 Scottish policy has significantly reduced household wealth by approximately $£ 7,200$. In addition, we observe heterogeneous household wealth across regions, with West Midlands, London, and North-East displaying the highest levels of household wealth and with the East and South East lagging behind. If the head of household has a partner, the average household saving is much higher, especially with respect to a divorced or separated head of household. Households with higher education save more, although the effect seems to peak for those who left education at ages 22-23. Household wealth is decreasing in the presence of young kids in the family, likely due to a larger consumption to face children's needs. Finally, savings are significantly lower when the status of the regional labour market is worse: one more percentage point in the regional unemployment rate translates into a decrease in wealth of about $£ 2,259$. When the status of the labour market worsens, it is more likely that a member of the household loses his/her job: savings are then used to finance the unemployment 
event and the search for a new job, resulting in the reduction of the household wealth.

Figure 3 shows that the age effect on household wealth has an inverted U-shaped profile, peaking in the late 50s. Kazarosian (1997) presents similar findings in the USA for the wealth-permanent income ratio, with a peak at age 57. This profile is consistent with the predictions of the life-cycle theory (Ando and Modigliani, 1957, 1963). According to the life-cycle hypothesis, individuals maximize their utility by taking into account the expected lifetime stream of earnings, so as to have a smooth consumption profile over time. When people are younger, their consumption needs are generally above their income, resulting in little wealth. In middle age earnings, savings generally rise due partially to the reduced risk of unemployment as well as career progression, allowing prime aged individuals to save more and accumulate wealth. Finally, when people retire from work, earnings decrease and the elderly might dissave to maintain a constant level of consumption. Moreover, retired individuals will face lower uncertainty with regards to the future income, reducing thereby the precautionary motive for savings (Leland, 1968; Sandmo, 1970; Kimball, 1990). Finally, the decreasing rate of dissaving for the eldest (see the right tail in Figure 3) is consistent both with the intergenerational altruism hypothesis, according to which people might save also for bequests (Kotlikoff, 1989), and with the precautionary motive, given that the eldest face a stable high risk of incurring in health expenditures.

Table 5: OLS estimation results of Eq. (1) for household wealth

\begin{tabular}{|c|c|c|c|c|c|c|}
\hline \multirow[b]{2}{*}{ Variable } & \multicolumn{3}{|c|}{$\begin{array}{c}\text { Fractional polynomial } \\
\text { age function }\end{array}$} & \multicolumn{3}{|c|}{$\begin{array}{l}\text { Non parametric } \\
\text { age function }\end{array}$} \\
\hline & Coeff. & & Std. Err. & Coeff. & & Std. Err \\
\hline After $*$ Scotland ${ }^{\S}\left(I_{r t}\right)$ & $-7,226.564$ & $* * *$ & $1,389.541$ & $-7,199.720$ & $* * *$ & $1,382.089$ \\
\hline Female & $-1,201.278$ & & 807.954 & $-1,199.601$ & & 800.345 \\
\hline Non-white & $-19,435.210$ & $* * *$ & $3,279.259$ & $-19,367.430$ & $* * *$ & $3,248.004$ \\
\hline \multicolumn{7}{|c|}{ Region of residence-Reference: North-East } \\
\hline North West and Merseyside & $-2,890.858$ & $*$ & $1,479.690$ & $-2,942.578$ & $*$ & $1,487.403$ \\
\hline Yorkshire and the Humber & $-3,852.879$ & $* *$ & $1,383.001$ & $-3,892.871$ & $* *$ & $1,395.609$ \\
\hline East Midlands & $-4,468.191$ & & $2,692.460$ & $-4,528.514$ & & $2,710.386$ \\
\hline West Midlands & $6,944.894$ & $* * *$ & $1,687.082$ & $6,892.979$ & $* * *$ & $1,675.744$ \\
\hline Eastern & $-12,643.410$ & & $8,490.494$ & $-12,820.200$ & & $8,516.126$ \\
\hline London & $10,057.980$ & & $12,536.220$ & $10,035.340$ & & $12,435.220$ \\
\hline South East & $-7,529.540$ & & $9,243.311$ & $-7,706.378$ & & $9,278.630$ \\
\hline South West & $-4,957.253$ & & $5,763.904$ & $-5,085.093$ & & $5,794.103$ \\
\hline Wales & $-5,160.094$ & $*$ & $2,778.925$ & $-5,217.265$ & $*$ & $2,783.426$ \\
\hline Scotland & $-5,458.247$ & $* *$ & $2,263.401$ & $-5,509.063$ & $* *$ & $2,253.363$ \\
\hline \multicolumn{7}{|l|}{ Civil status - Reference: Divorced } \\
\hline \multicolumn{7}{|c|}{ Continued on next page } \\
\hline
\end{tabular}


Table 5 - continued from previous page

\begin{tabular}{|c|c|c|c|c|c|c|}
\hline \multirow[b]{2}{*}{ Variable } & \multicolumn{3}{|c|}{$\begin{array}{l}\text { Fractional polynomial } \\
\text { age function }\end{array}$} & \multicolumn{3}{|c|}{$\begin{array}{l}\text { Non parametric } \\
\text { age function }\end{array}$} \\
\hline & Coeff. & & Std. Err. & Coeff. & & Std. Err. \\
\hline Married & $13,977.310$ & $* * *$ & $3,287.591$ & $14,006.020$ & $* * *$ & $3,316.107$ \\
\hline Couple & $16,183.900$ & $* * *$ & $1,976.177$ & $16,107.230$ & $* * *$ & $1,960.995$ \\
\hline Single & $6,828.915$ & $* * *$ & $1,632.155$ & $6,772.876$ & $* * *$ & $1,623.702$ \\
\hline Widowed & $8,336.850$ & $* * *$ & $1,018.158$ & $8,366.216$ & $* * *$ & $1,049.981$ \\
\hline Separated & $1,887.105$ & & $1,416.496$ & $1,869.012$ & & $1,421.110$ \\
\hline \multicolumn{7}{|l|}{ Education: Age left - Reference: 28 and above } \\
\hline $0-12$ & $-6,354.738$ & $*$ & $2,945.604$ & $-6,397.714$ & $*$ & $3,016.508$ \\
\hline $13-15$ & $-12,233.530$ & $* * *$ & $1,501.058$ & $-12,397.440$ & $* * *$ & $1,483.993$ \\
\hline $16-18$ & $8,277.405$ & $* * *$ & $2,288.767$ & $8,170.862$ & $* * *$ & $2,277.436$ \\
\hline $19-21$ & $20,024.450$ & $* * *$ & $2,076.701$ & $19,891.410$ & $* * *$ & $2,058.548$ \\
\hline $22-23$ & $20,850.200$ & $* * *$ & $2,645.414$ & $20,726.590$ & $* * *$ & $2,633.481$ \\
\hline $24-27$ & $15,353.940$ & $* * *$ & $2,265.582$ & $15,137.190$ & $* * *$ & $2,237.984$ \\
\hline \multicolumn{7}{|c|}{ Education of the spouse: Age left - Reference: Single } \\
\hline $0-12$ & $1,145.006$ & & $1,926.423$ & $1,052.197$ & & $1,976.518$ \\
\hline $13-15$ & $10,153.820$ & $* *$ & $4,522.154$ & $9,963.090$ & $*$ & $4,542.015$ \\
\hline $16-18$ & $24,881.160$ & $* * *$ & $6,507.686$ & $24,816.560$ & $* * *$ & $6,522.372$ \\
\hline $19-21$ & $33,000.420$ & $* * *$ & $7,010.547$ & $32,912.000$ & $* * *$ & $7,020.382$ \\
\hline $22-23$ & $30,282.810$ & $* * *$ & $7,070.713$ & $30,247.760$ & $* * *$ & $7,064.735$ \\
\hline $24-27$ & $23,207.230$ & $* * *$ & $5,264.962$ & $23,068.490$ & $* * *$ & $5,270.583$ \\
\hline 28 and above & $14,950.280$ & $* *$ & $5,356.231$ & $15,215.610$ & $* *$ & $5,342.169$ \\
\hline Presence of kids $<5$ years & $-4,459.268$ & $* * *$ & 463.888 & $-4,614.616$ & $* * *$ & 471.738 \\
\hline Presence of kids $[5,11)$ years & $-1,284.284$ & $* *$ & 452.368 & $-1,390.090$ & $* *$ & 447.465 \\
\hline Presence of kids $[11,15)$ years & -708.426 & & 526.745 & -490.483 & & 482.434 \\
\hline Regional unemployment rate by gender & $-2,259.023$ & $* * *$ & 490.344 & $-2,246.250$ & $* * *$ & 490.175 \\
\hline Per capita regional gross value added & -3.872 & $*$ & 2.051 & -3.901 & $*$ & 2.038 \\
\hline Per capita regional gross disposable income & 19.500 & $* * *$ & 5.030 & 19.589 & $* * *$ & 5.021 \\
\hline Variation of per capita reg. gross value added & 3.543 & & 2.431 & 3.589 & & 2.405 \\
\hline $\begin{array}{l}\text { Variation of per capita reg. gross disposable inc. } \\
\text { Tax year dummies - Reference: } 1999\end{array}$ & -20.857 & $* * *$ & 4.011 & -20.962 & $* * *$ & 4.041 \\
\hline 2000 & -915.235 & & $2,260.953$ & -924.716 & & $2,247.023$ \\
\hline 2001 & $-3,962.513$ & & $3,508.857$ & $-4,036.863$ & & $3,479.269$ \\
\hline 2002 & $-6,512.889$ & & $5,429.320$ & $-6,654.433$ & & $5,417.930$ \\
\hline 2003 & $-6,686.723$ & & $6,141.528$ & $-6,893.592$ & & $6,134.749$ \\
\hline 2004 & $-5,790.310$ & & $6,907.522$ & $-5,955.827$ & & $6,902.855$ \\
\hline 2005 & $-5,091.838$ & & $7,902.415$ & $-5,273.062$ & & $7,890.233$ \\
\hline 2006 & $-8,593.245$ & & $8,133.211$ & $-8,772.822$ & & $8,152.990$ \\
\hline 2007 & $-10,000.870$ & & $9,299.764$ & $-10,157.930$ & & $9,320.976$ \\
\hline Constant & $5,107,066.000$ & $* * *$ & $551,534.400$ & $-138,607.900$ & $* * *$ & $27,550.610$ \\
\hline Observations & & 58,562 & & & 58,562 & \\
\hline$R^{2}$ & & 0.262 & & & 0.263 & \\
\hline \# of clusters & & 11 & & & 11 & \\
\hline \# of parameters & & 55 & & & 75 & \\
\hline $\begin{array}{l}\text { Notes: } * * * \text { Significant at } 1 \% ; * * \text { significant at } 5 \\
\text { and } t_{R-1} \text { critical values as suggested in Brew } \\
\text { relation between the age of the head of househ } \\
\text { between age and wealth are instead depicted in }\end{array}$ & $\begin{array}{l}; * \text { significant at } \\
\text { et al. (2013). I } \\
\text { d and househol } \\
\text { gure } 3 \text {. }\end{array}$ & $\begin{array}{l}10 \% \text {. } \\
\text { or the } \\
\text { I weal }\end{array}$ & $\begin{array}{l}\text { LS with } \sqrt{R} \\
\text { ake of brevity } \\
\text { are not repor }\end{array}$ & $\begin{array}{l}-1 \text { - } \text {-cluster } \\
\text { parameters } \\
\text { in this table. }\end{array}$ & $\begin{array}{l}\text { robu } \\
\text { termi } \\
\text { he es }\end{array}$ & $\begin{array}{l}\text { standard erro } \\
\text { ng the flexib } \\
\text { nated relatio }\end{array}$ \\
\hline
\end{tabular}


Figure 3: The relation between the age of the head of household and household wealth

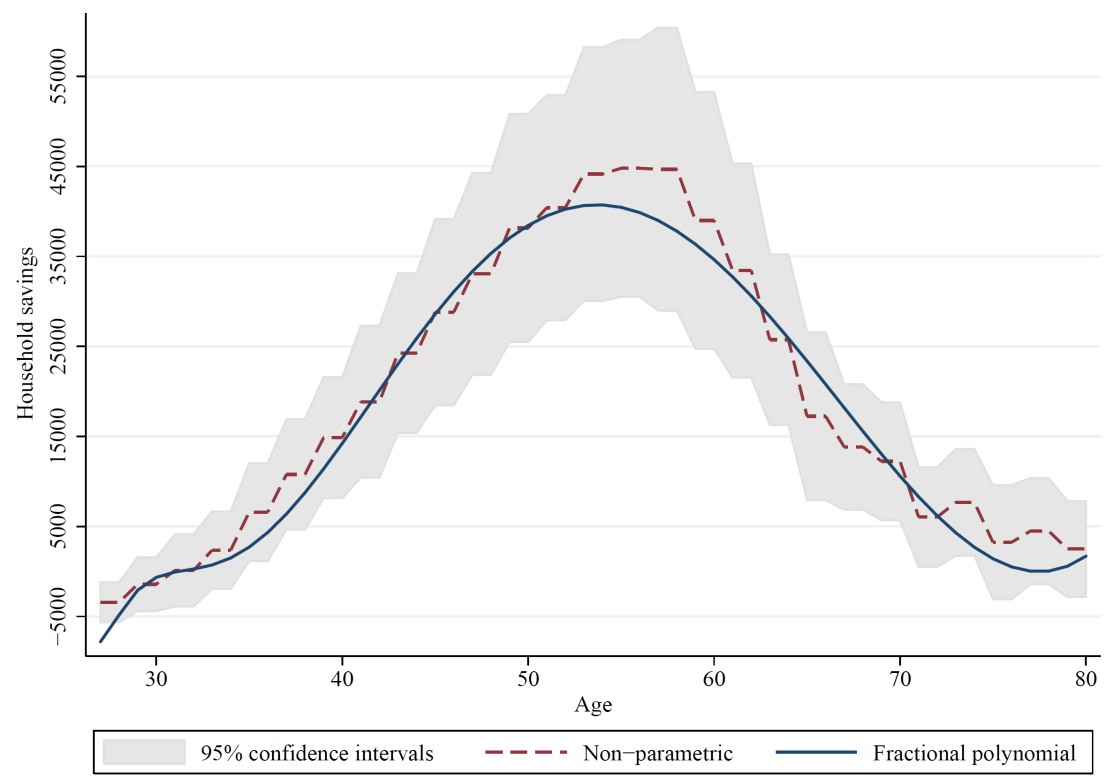

Notes: Household wealth is normalized to zero at 25 years of age of the head of household.

\subsection{Estimated effects of the reform across age}

As mentioned in Subsection 3, the policy effects on household wealth may vary with the age of the head of household. Figure 4 displays the heterogeneous effect of the 2002 policy reform by the age of the head of household. Estimating Eq. (2) by OLS, we impose fractional polynomial specification of the age functions with powers $\{-2,-1,-0.5,0,1$, $2,3\}$, as well as piecewise constant functions by grouping age in intervals of two years. For the sake of brevity, the full set of estimation results are reported in Appendix B in Tables B.3 and B.4. ${ }^{14}$ Both the fractional polynomial and the piecewise constant specifications of the age functions return very similar results. On the one hand, the fractional polynomial approach has the advantage of smoothing peaks that might be due to random outlier observations, at a cost of relying more on a parametric structure. On the other hand, the piecewise constant approach is less parametric and, in this application, it is preferred according to the LOOCV statistic.

We find that the policy effect indeed varies across the age of the head of household.

\footnotetext{
${ }^{14}$ Since the estimated parameters of all the other regressors are quite robust and close to those reported in Table 5, we do not comment on them.
} 
When the head of household is aged 25-35, and therefore the household members have a long time horizon until the possible need of personal care, the effect of the reform is negative but close to zero. In their mid $30 \mathrm{~s}$, households start reacting by reducing their wealth. The age profile of the reform effect peaks between 45 and 55 years. With the fractional polynomial specification, the peak is reached at age 49 with a decrease in household wealth of $£ 12,764$. In the piecewise constant specification, we instead observe two important peaks: the first one at age 43-44, with a decrease in household wealth of $£ 16,827$; the second one at age $51-52$, with a negative effect of $£ 15,441$. Finally, the reform effect becomes nil when the age of the head of household approaches 65-70.

Figure 4: The effects of the reform on household wealth by the age of the head of household
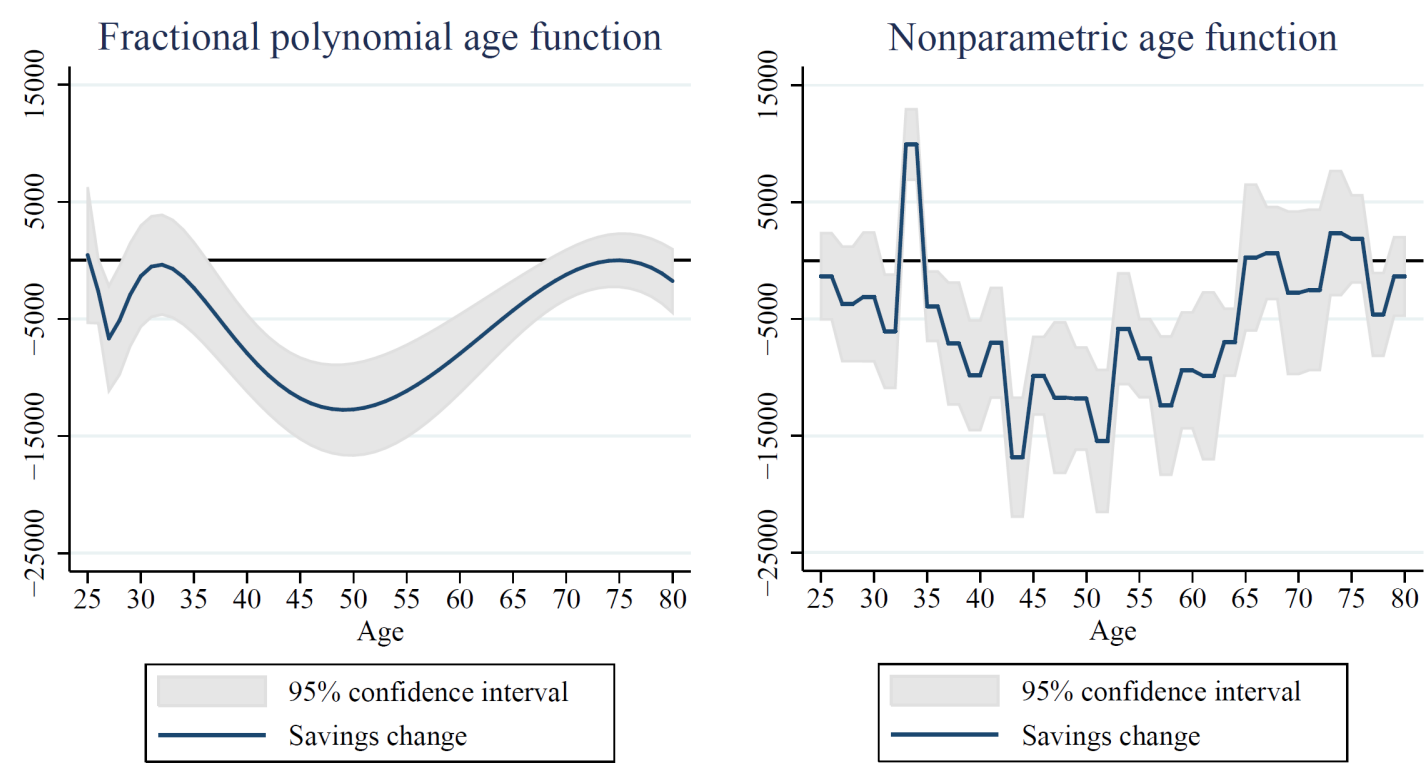

Interpreting these results in light of the theoretical discussions in Section 3, the three channels seem to offset each other for the young and near retirement households, leaving them to change their wealth behaviour in a limited manner. Middle aged households were instead predicted to be exposed to the strongest incentive to reduce wealth and this is in line we what we observe here. 


\subsection{Estimated effect of reform on the main components of household wealth}

In this subsection we try to clarify the mechanisms through which the observed reduction in the household wealth occurred. We split the dependent variable in its three main components (bank deposit, house value, and mortgages) and study how the Scottish personal care reform affected them separately. We also study the effect on an additional variable, a dummy indicator which equals to 1 if the household purchases a house during the observed year and zero otherwise. Investigation of this variable allows us to study whether the wealth behaviour changed at the extensive margin (i.e. whether individual households changed their house purchasing behaviour). The DD approach and the set of covariates used to linearly model the conditional mean of these new dependent variables are the same as those used in the benchmark model.

Figure 5: The effect of the reform on the main components of household wealth by the age of the head of household

(a) Change in probability of purchasing a house

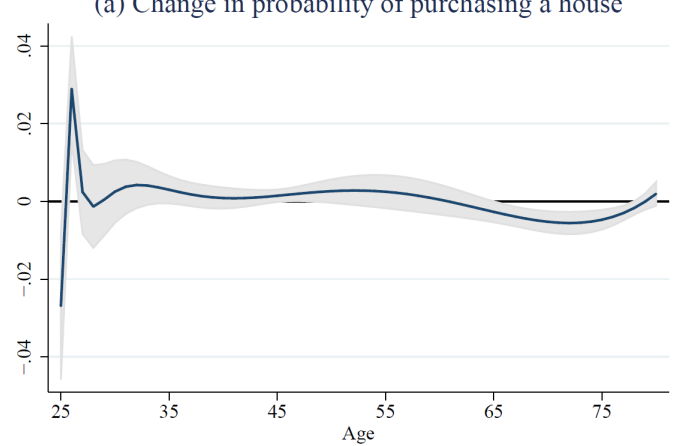

(c) Change in mortgages

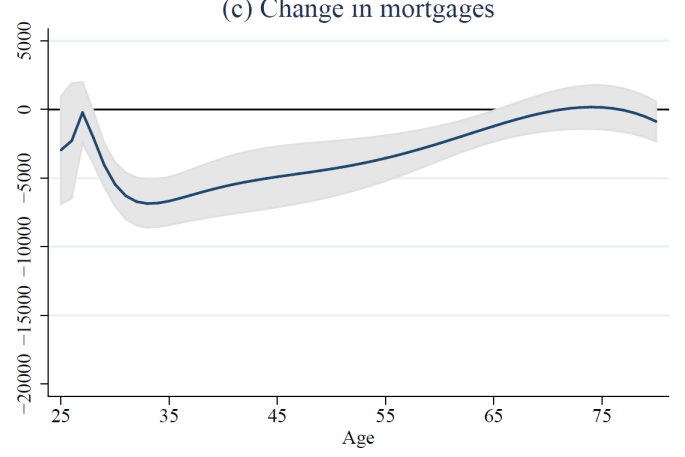

(b) Change in house value

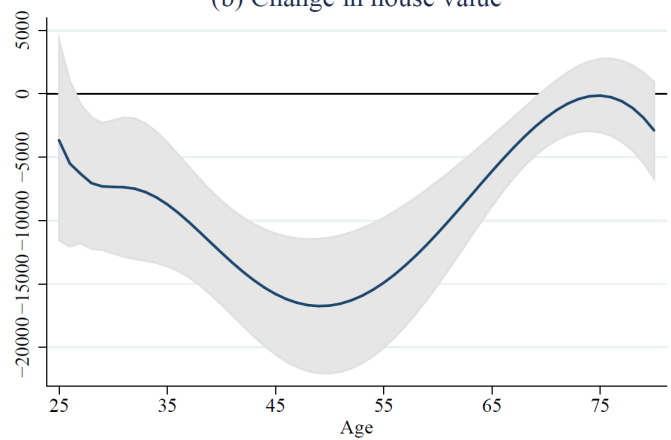

(d) Change in bank deposit

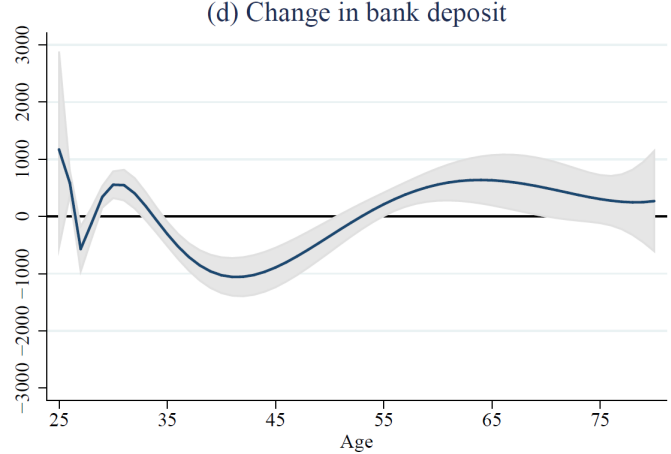

Figure 5 depicts the policy effects on the four outcome variables by the age of the 
head of household. Graph (a) indicates that the probability of purchasing a house did not change after the policy introduction. It, therefore, rules out the possibility that our results are capturing changes in the extensive margin of wealth. The other three graphs strongly indicate that the policy effects are rather heterogeneous across age of the head of household. Moreover, Figure 5 also highlights that the U-shaped relation presented in Figure 4 is mainly determined by the change in house values and, to a smaller extent, by the variation in mortgages and the bank deposit. These graphs suggest a potential story that households reduced the value of the houses they purchased as they no longer need to accumulate wealth to pay for future care cost. This line of reasoning is plausible provided that Scottish households had to sell their houses to finance their care at the end of their lives if they were moving into residential care homes (Department of Health, 2003a,b). ${ }^{15}$ In fact, the policy was likely to have encouraged the elderly to remain in their own homes for a longer period and thus there was less need to sell their houses to finance their care at the end of their lives.

\subsection{Estimated effect of reform across time}

In this subsection we present the effect of the reform over time, to investigate whether the reform had a temporary or a permanent shock on the level of household wealth. We modified Eq. (2) so as to get an age varying policy effect which is allowed to differ across years after the reform, i.e.

$$
y_{i r t}=\mathbf{x}_{i r t}^{\prime} \boldsymbol{\beta}+\boldsymbol{\gamma}_{r}\left(a g e_{i r t}\right)+\sum_{g=1}^{3} \phi_{t g}\left(a g e_{i r t}\right)+\sum_{g=1}^{3} \boldsymbol{\delta}_{D D g}\left(a g e_{i r t}\right) I_{r t}+\varepsilon_{i r t}
$$

where $g=1$ denotes years 2002-2003, $g=2$ denotes years 2004-2005, and $g=3$ denotes years 2006-2007.

In order to save in terms of degrees of freedom, we employ the fractional polynomial specification discussed in the previous section. Figure 6 depicts the age heterogeneous reform effect on household wealth by years. It shows that the reactions of households to the reform is immediate and reaches its maximum effect in the biennium 2004-2005. In 2006-2007, the reform effect is slightly reduced, although the magnitude is still relevant and significantly different from zero for households with household heads between 39 and 64 years of age.

\footnotetext{
${ }^{15}$ This is also true for households in the rest of UK (Department of Health, 2003a,b).
} 
The public's gradual learning of the 2002 policy may offer one potential explanation for this finding. Bell et al. (2006) report that the Scottish individuals appeared to have misunderstood the policy and assumed that the personal care would be an automatic entitlement and offered to them without any health assessment. This may be due to the fact that the media described the policy as "free personal care" without describing in detail the process required to acquire the allowances (e.g. Inman, 2002). The reduction over time in the size of the policy effect may indicate that households made saving readjustments after obtaining more complete information on the degree of the cost coverage offered by this policy.

Figure 6: The time-varying effects of the reform on household wealth by the age of the head of household
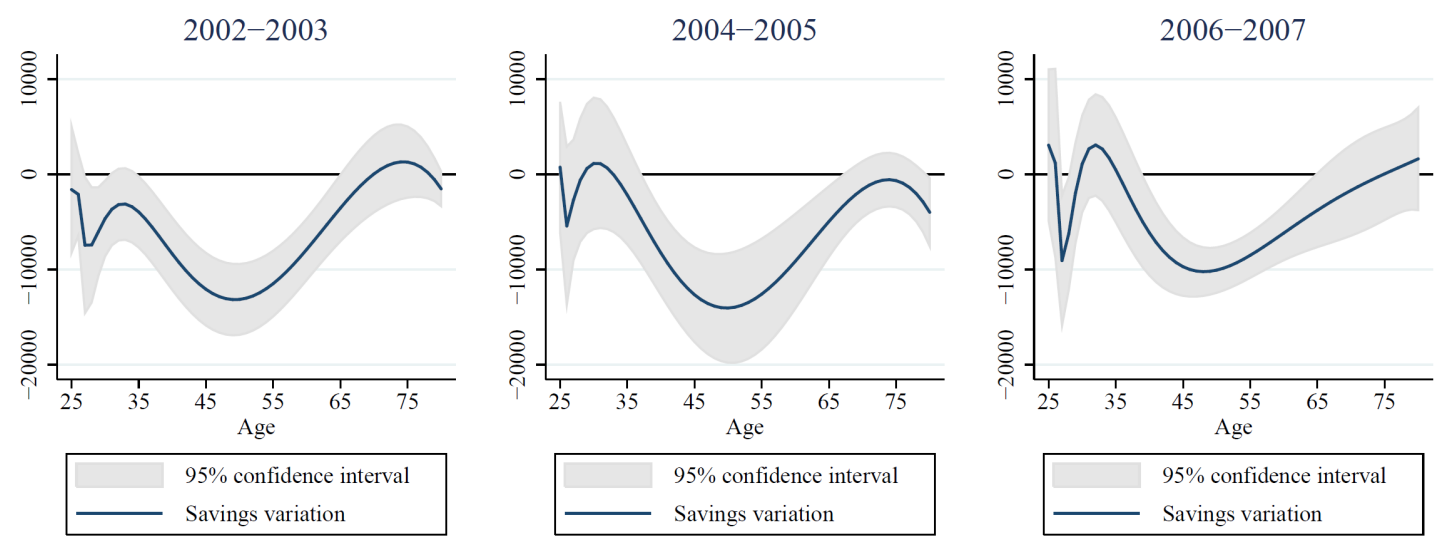

\section{Sensitivity analysis}

We conduct various sensitivity analyses in order to test the robustness of our baseline findings. First, we run a placebo test by including among the regressors the lag of order one and order two of the policy indicator $I_{r t}$ and testing the significance of the associated coefficients. ${ }^{16}$ We reject the null hypothesis of joint significance of these lagged policy indicators. ${ }^{17}$ This supports the validity of the parallel trend and no anticipation assump-

\footnotetext{
${ }^{16}$ Since we have only three periods before the reform, we cannot include further lags.

${ }^{17}$ In the model with homogeneous policy effect across age, we cannot reject the null hypothesis with a $p$-value equal to 0.205 . Similarly, the $p$-value is 0.132 for the model with heterogeneous policy effects across age.
} 
tions.

In a second sensitivity analysis, we exclude families with children and individuals in education from our sample. Scotland followed a separate path from England and Wales with regards to the issue of the university tuition fees. In 1998, tuition fees were introduced across the UK. At this point, $£ 1,000$ per year was charged as a tuition fee for all students. Whilst England and Wales subsequently increased their university tuition fees to $£ 3,000$ in 2004 and $£ 9,000$ in 2009, Scotland abolished tuition fees in 2001 for Scottish students who chose to study in Scotland. ${ }^{18}$ Instead of charging tuition fees, Scottish students were asked to repay $£ 2,000$ after they graduate and start earning at least $£ 10,000$ a year. The cheaper university tuition fees in Scotland compared to those in England and Wales may have further reduced the incentives to save for the Scottish families with children or with members still in education, introducing a confounding effect in the interpretation of our findings. As a result, we check whether the results are stable when we exclude families with children and individuals in education from the sample. ${ }^{19}$ The graph in panel (a) in Figure 7 presents the policy effect by age when we remove families with children and individuals in education. We find estimation results that are very much in line with those of the benchmark model.

In a third sensitivity analysis, we exclude years 2001 and 2002 from our sample. This is partially due to eliminating any policy anticipation effects. From the time the Sutherland Commission was set up, the entire process until the enactment of the Scottish CCHA was highly publicized by the media. Moreover, the Scottish government's decision to take up the recommendation received wide media coverage as early as January 2002. For example, the BBC announced that the free personal care for Scotland would be introduced in July of the same year on 15 January 2002. Similarly, the Guardian also published an article after one of the Bills passed in the Scottish Parliament (Inman, 2002). As a result of this wide media coverage, households may have anticipated the introduction of the policy. If this were the case, including the observations from 2001 would positively bias our results. However, graph (b) of Figure 7 clearly indicates that excluding these two years from our sample does not affect the estimated policy effects. ${ }^{20}$

Up until now, we conducted our analysis for the years between 1999 and 2007. As our fourth check, we test if our results are sensitive to the years that we selected for our

\footnotetext{
${ }^{18}$ If the student is English, (s)he would still have to pay the tuition fees even if studying in Scotland.

${ }^{19}$ The sample size shrinks to 93,534 households, of which 15,932 are Scottish and 12,494 are Scottish after the personal care reform.

${ }^{20}$ After eliminating 2001 and 2002 observations, we are left with 121,069 households, of which 19,336 are Scottish and 15,825 are Scottish after 2002.
} 
analysis. We, therefore, also include 1998 observations in our sample. ${ }^{21}$ Graph (c) of Figure 7 confirms the robustness of the policy effect of the estimated benchmark model. ${ }^{22}$

Fifth, we remove households living in London from our sample. ${ }^{23}$ This is because London is likely to differ substantially from the rest of UK in terms of its economic activities and demographic characteristics such as migration movements (Duranton and Monastiriotis, 2002; Hatton and Tani, 2005). This suggests that households residing in London iare unlikely to be a valid control group for the Scottish households. Once we delete households living in London from the sample, we actually find that the policy effect is stronger in magnitude, as depicted in graph (d) of Figure 7. The effect is significantly different from zero at all ages, but 25 . The strongest reduction in wealth is recorded at age 50 with a decrease in household wealth of about $£ 16,627$. This results indicate that if the households living in London are not a valid control group, their inclusion in the benchmark model determines a lower bound in the negative effect of the policy on wealth.

Finally, we assess the robustness of the identification strategy by using an alternative strategy. Our difference-in-differences method assumes that individuals residing in Scotland would behave in exactly the same way as those in England and Wales in the absence of the policy introduction. This assumption, however, may be too strict if there are region specific trends. We, therefore, apply the triple difference estimator proposed by Gruber (1994). The triple difference estimator uses another control group in addition to our original control group (i.e. those residing in England and Wales). This additional control group should be present in both Scotland as well as England/Wales but must be unaffected by the Scottish policy introduction. The main function of this additional control group is to take away any differential trends experienced by those residing in Scotland vs England/Wales.

When applying a difference-in-differences estimator, we included the following terms in the wealth equation:

- tax year fixed effects $\phi_{t}$ to capture the UK trend in wealth;

- regional fixed effects $\gamma_{t}$ to control for secular differences in wealth of Scotland and the other control regions;

\footnotetext{
${ }^{21}$ We cannot use observations prior to 1998 because the aggregate variables used to control for regional specific trends, gathered by the Office for National Statistics (ONS), are only available from 1997. In addition, since we use the time variation of these aggregate regional variables, we also lose 1997.

${ }^{22}$ When we include 1998 observations, our sample contains 175,491 households, of which 26,332 are Scottish.

${ }^{23}$ When we exclude households living in London from our sample, the sample size becomes 140,472 observations.
} 
Figure 7: The sensitivity test of the policy effects on household wealth
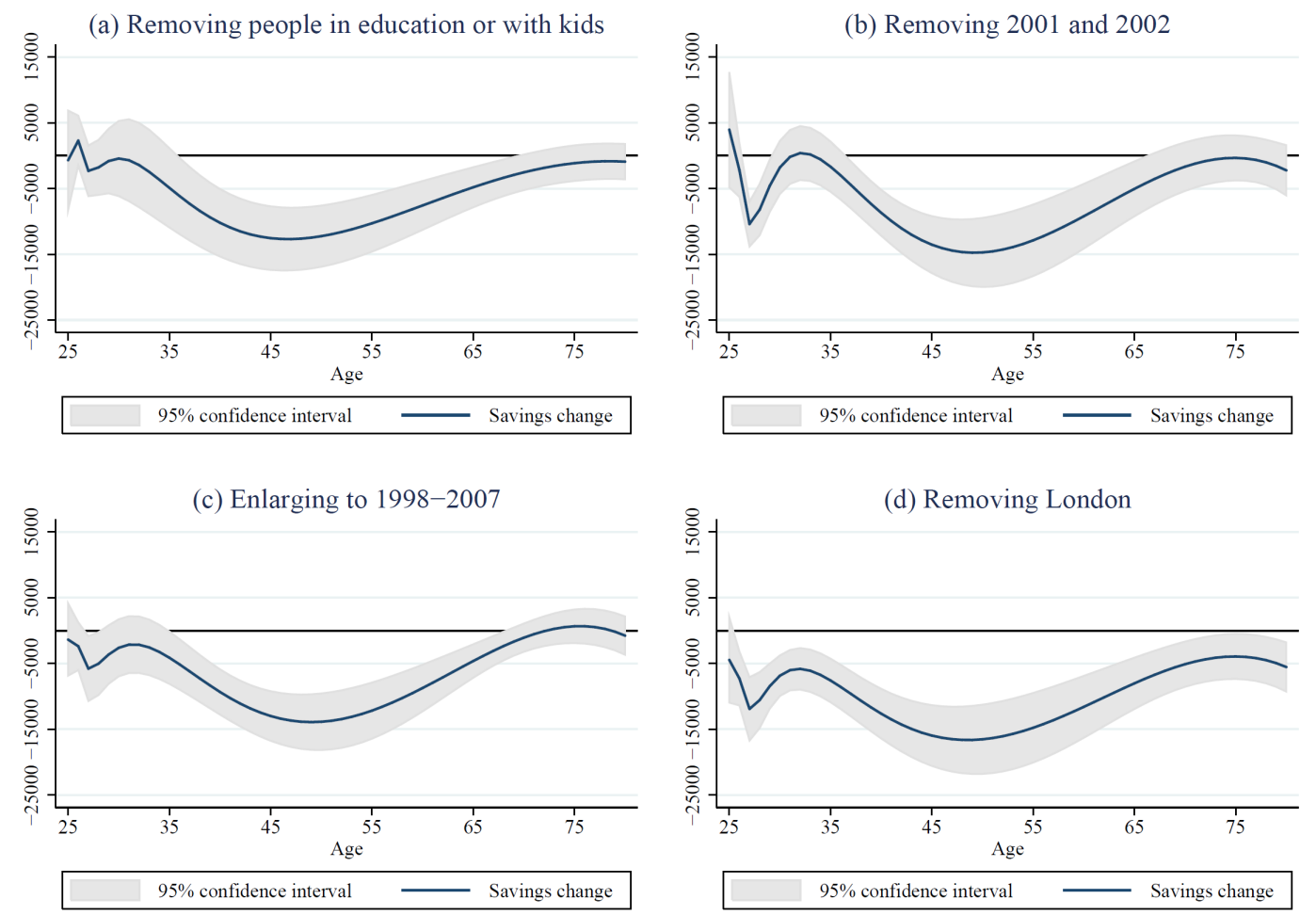
- time-varying regressors at regional level within $\mathbf{x}_{i r t}$ to proxy regional-specific shocks that might have affected wealth during the period of the policy reform.

In this last sensitivity analysis, we remove the time-varying regressors at regional level from the specification of the wealth equation. Instead, we replace them by a full set of interactions between tax year indicators and regional indicators, and we define young individuals aged between 25-30 in Scotland as belonging to the control group. We assume that young individuals are unaffected by the policy as they do not internalise and plan for old age expenditures. ${ }^{24}$ If this assumption is correct, we can identify the policy effect without the need of the common trend. The interactions between the tax year and the regional indicators will indeed capture and estimate differential unobserved time trends in wealth across regions. As pointed out by Gruber (1994), the assumption for the consistency of a DDD estimator are fairly weak, since it requires that there should not be contemporaneous shocks affecting the wealth of the treated in the same year as the policy. However, if the assumption that young Scottish individuals are not affected by the introduction of free personal care fails, then the DDD estimator will return a biased upward policy effect provided that wealth of young individuals are negatively affected by the reform. In such a case, our DDD estimates can be interpreted as an upper bound of the introduction of free personal care on household wealth.

In order to implement the DDD strategy, we assume the absence of policy effects for households with the head of household strictly younger than 31 years of age. This assumption seems to be supported by the results shown in the right graph of Figure 4. Indeed we cannot reject the null hypothesis of zero effect for households with heads strictly younger than 31 after the estimation of Eq. (2) ( $p$-value equal is 0.430). The DDD estimated policy effect, under the assumption of homogeneous treatment effect for heads of household older than 30 , is equal to $-4,598.15$ and significant at the $1 \%$ significance level. The difference between the DD estimate presented in Table 5 and the DDD estimate is equal to $£-2,628.42$ and it is not significantly different from zero ( $p$-value $=0.109){ }^{25}$ Table 6 reports the estimated DDD effect when it is assumed to be homogeneous across age and when it is allowed to vary across the age of the head of household. The DDD estimates by age confirm the robustness of the findings of our benchmark estimates.

\footnotetext{
${ }^{24}$ In a stochastic life-cycle model, one could impose for example that households suffer from a present bias and put extra weight on the consumption in periods closer to the present (Laibson, 1998). Young individuals aged between 25-30 are so far away from retirement that they might discount utility streams in 35-40 years with a factor tending to zero.

${ }^{25}$ We test the significance of the difference of the two coefficients by bootstrapping (500 replications). The bootstrapped standard error of the difference of the DD and DDD estimates is 1,640.78.
} 
Table 6: DDD estimates of the reform effects

\begin{tabular}{lrlrrr}
\hline \hline DDD policy effect & Coeff. & & Std. Err. & \# observations & $R^{2}$ \\
\hline Total sample & $-4,598.147$ & $* * *$ & $1,385.118$ & 158,562 & 0.265 \\
By the age of the household head & & & & & \\
31-35 & $3,078.651$ & $* *$ & $1,087.789$ & 42,634 & 0.155 \\
$36-40$ & $-5,707.607$ & $* * *$ & $1,436.518$ & 43,987 & 0.198 \\
$41-45$ & $-7,576.726$ & $* * *$ & $1,640.226$ & 41,353 & 0.224 \\
$46-50$ & $-9,731.581$ & $* * *$ & $1,826.096$ & 38,024 & 0.276 \\
$51-55$ & $-7,154.817$ & $* *$ & $2,896.706$ & 35,492 & 0.281 \\
$56-60$ & $-8,741.534$ & $* * *$ & $2,187.733$ & 31,891 & 0.263 \\
$61-65$ & $-5,132.961$ & $* *$ & $2,181.518$ & 28,700 & 0.182 \\
$66-70$ & 192.205 & & $2,489.034$ & 26,869 & 0.136 \\
$71-75$ & $1,730.511$ & & $2,386.937$ & 26,497 & 0.140 \\
76 or more & 506.769 & & $1,175.629$ & 32,034 & 0.137 \\
\hline
\end{tabular}

Notes: $* * *$ Significant at $1 \%$;* significant at $5 \%$; * significant at $10 \%$

\section{Conclusions}

This paper studies the impact of the Scottish Care and Health Act 2002 on the level of household wealth. The Scottish policy legislated that formal personal care be offered to the elderly free of charge. In contrast, the rest of UK have continued to charge the elderly for service. If households save to prepare for the future elderly care expenditure, such a reduction in the care price may have led the households to respond by reducing their level of wealth. This paper, therefore, studies an unintended consequence of the policy introduction and evaluate if and to what extent it crowded out private savings.

By using the households in England and Wales as a control group, we investigate how the Scottish household wealth responded to the policy introduction of free personal care for the elderly by using a difference-in-differences estimator. We also study how the effect differs across age by using semi-parametric techniques.

We find that the Scottish policy reform reduced the average household wealth by about $£ 7,200$. This figure is very close to the simulated expected lifetime cost of local authority provided personal care reported by Comas-Herrera and Wittenberg (2010). In their paper, they estimate the cost to be $£ 8,800$. In addition, we find that the policy effect varies across the age of the head of household. The estimated negative effect is particularly strong among households aged between 40 and 60. The largest effect is observed for those households with the heads aged 49 , with a negative effect on wealth of $£ 12,764$. Our findings are in line with the existing literature for the US, which also suggests the importance of medical expenditure uncertainties on household savings behaviour (Gruber and Yelowitz, 1999; Maynard and Qiu, 2009). However, our findings differ from those 
presented by Guariglia and Rossi (2004), who instead found that British individuals do not make use of precautionary savings against the risk of facing unexpected private health care expenditures. This may be due to the fact that UK individuals have access to universal health care coverage through the NHS. Hence, the health insurance coverage that Guariglia and Rossi (2004) investigated had limited impacts on individuals' behaviour. In contrast, our policy offered a substantial long-term care cost reduction under the environment where this type of cost was almost exclusively paid by patients. In order to ensure that our estimates uncover causal relationships, we conduct several identification tests as well as sensitivity analyses. Our findings from various tests and the sensitivity analyses strongly indicate the robustness of our conclusions from the estimates of the benchmark model.

Given the sizeable effect on wealth, especially for middle aged households, one may wonder if households over-estimated the benefits introduced by the free personal care reform due to a misunderstanding of the policy, as pointed out by Bell et al. (2006). If so, the resulting reduction in precautionary savings might lead to a situation in which there is less than full insurance against long-term care for the elderly. In such a case, one might wonder whether universal elderly care insurance introduced in countries such as Japan or Germany may be a more effective way to address the large and volatile risks of long-term care for the elderly. These questions are left to be investigated in future studies.

\section{References}

Ando, A. and F. Modigliani (1957). Tests of the life cycle hypotheses of savings: Comments and suggestions. Bulletin of the Oxford University Institute of Economics \& Statistics 19(2), 99-124.

Ando, A. and F. Modigliani (1963). The "life cycle" hypothesis of saving: Aggregate implications and tests. American Economic Review 53(1), 55 - 84.

Bell, D., A. M. Bowes, et al. (2006). Financial care models in Scotland and the UK. Joseph Rowntree Foundation York.

Brewer, M., T. Crossley, and R. Joyce (2013). Inference with difference-in-differences revisited. IZA Discussion Paper No. 7742, Bonn.

Comas-Herrera, A. and R. Wittenberg (2010). Expected lifetime costs of social care for people aged 65 and over in England. In L. Curtis (Ed.), Unit Costs of Health and Social Care, Canterbury, pp. 41-46. Personal Social Services Research Unit. 
De Nardi, M., E. French, and J. B. Jones (2010). Why do the elderly save? The role of medical expenses. Journal of Political Economy 118(1), pp. 39-75.

Department of Health (2003a). Charging for residential accommodation guide (CRAG): In support of the national assistance (assessment of resources) regulations 1992. United Kingdom Government.

Department of Health (2003b). Fairer charging policies for home care and other non-residential social services: Guidance for Councils with social services Responsibilities. United Kingdom Government.

Duranton, G. and V. Monastiriotis (2002). Mind the gaps: The evolution of regional earnings inequalities in the U.K., 1982-1997. Journal of Regional Sciences 42(2), 219 - 256.

Frederick, S., G. Loewenstein, and T. O'Donoghue (2002). Time discounting and time preference: A critical review. Journal of Economic Literature 40(2), 351-401.

Gruber, J. (1994). The Incidence of Mandated Maternity Benefits. American Economic Review 84(3), 622-41.

Gruber, J. and A. Yelowitz (1999). Public health insurance and private savings. Journal of Political Economy 107(6), pp. 1249-1274.

Guariglia, A. (2001). Saving behaviour and earnings uncertainty: Evidence from the British Household Panel Survey. Journal of Population Economics 14(4), 619 - 634.

Guariglia, A. and M. Rossi (2004). Private medical insurance and saving: Evidence from the British Household Panel Survey. Journal of Health Economics 23(4), 761 - 783. Contains contributions from the Grossman Symposium.

Hatton, T. and M. Tani (2005). Immigration and inter-regional mobility in the UK, 1982-2000. Economic Journal 115(507), F342-F358.

Hubbard, R. G., J. Skinner, and S. P. Zeldes (1994). Expanding the life-cycle model: Precautionary saving and public policy. The American Economic Review 84(2), pp. 174-179.

Inman, P. (2002, 23 March). Free and easy for the Scots. The Guardian. Retrieved from http://www.theguardian.com/society/2002/mar/23/longtermcare.housinginretirement3.

Kazarosian, M. (1997). Precautionary savings - A panel study. Review of Economics and Statistics 79(2), $241-247$.

Kimball, M. S. (1990). Precautionary saving in the small and in the large. Econometrica 58(1), $53-73$.

Kopecky, K. A. and T. Koreshkova (2014). The impact of medical and nursing home expenses on savings. American Economic Journal: Macroeconomics 6(3), 29-72. 
Kotlikoff, L. J. (1989). Health expenditures adn precautionary savings. Cambridge, MA: MIT Press.

Krueger, D. and F. Perri (2010). How do households respond to income shocks? Mimeo, University of Pennsylvania.

Laibson, D. (1998). Life-cycle consumption and hyperbolic discount functions. European Economic Review 42(3-5), $861-871$.

Leland, H. E. (1968). Saving and uncertainty: The precautionary demand for saving. Quarterly Journal of Economics 82(3), 465 - 473.

Lucas, R. J. (1988). On the mechanics of economic development. Journal of Monetary Economics 22(1), 3-42.

Maynard, A. and J. Qiu (2009). Public insurance and private savings: Who is affected and by how much? Journal of Applied Econometrics 24(2), 282-308.

National Statistics (2002). Community Care Statistics 2001: Home care services for adults, England. National Statistics, Department of Health, London.

National Statistics (2012). Free Personal and Nursing Care, Scotland, 2010-11. National Statistics Publication for Scotland, Edinburgh.

Netten, A., J. Francis, A. Bebbington, L. Curtis, and K. Hamilton-West (2003). Costs, quality and outcomes. PSSRU Bulletin No.14.

Palumbo, M. G. (1999). Uncertain medical expenses and precautionary saving near the end of the life cycle. The Review of Economic Studies 66(2), pp. 395-421.

Romer, P. (1986). Increasing returns and long-run growth. Journal of Political Economy 94(5), 1002-1037.

Sandmo, A. (1970). The effect of uncertainty on saving decisions. Review of Economic Studies 37(3), $353-360$.

Scholz, J. K., A. Seshadri, and S. Khitatrakun (2006). Are Americans saving "optimally" for retirement? Journal of Political Economy 114(4), 607-643.

Solow, R. (1959). A contribution to the theory of economic growth. Quarterly Journal of Economics 70(1), 65-94. 


\section{Appendix}

\section{A Other policy reforms}

In addition to the 2002 Scottish CCHA, there were other reforms that influenced the elderly care cost, which contributed to the changes in the amount of allowances individuals received. As stated below, however, these policies were implemented throughout the UK and it is the free personal care element of the 2002 CCHA reform that contributed to the substantially larger increase in the amount of allowances Scottish individuals received compared to those living elsewhere in UK.

\section{A.1 Nursing care cost}

Nursing care is the type of care that involves medical care provided by registered nurses. Prior to 2001, nursing care provided in UK care homes was maintained by social services administered by each local authority. Financial support for nursing care was only offered on stringent means-tested basis. In contrast, nursing care offered at home or in hospitals was organized by the National Health Service (NHS) and, therefore, was free of charge at the point of delivery.

In response to the 1999 Sutherland report, which recommended that both personal and nursing care be offered free of charge regardless of care settings, England and Wales each implemented their free nursing care policy in October and December 2001. Scotland and Northern Ireland introduced their policy in June and October 2002, respectively. They paid allowances directly to care homes where the individual is receiving nursing care. The policy change, therefore, was aimed at correcting the unequal cost treatment for patients receiving nursing care in care homes compared to those receiving free nursing care either at home or in hospitals.

\section{A.2 Attendance Allowances}

The Attendance Allowance (AA) is a non-means tested weekly benefit for severely disabled people aged 65 or over who need help with personal care. It is paid out to all UK individuals in need. The amount of AA depends on the severity of the elderly's disability. After local authorities assess the elderly's condition, allowances are paid out in two levels depending on the elderly's condition.

After the 2002 CCHA reform, Scottish individuals receiving free personal care in care homes no longer qualified to receive AA. In contrast, those Scottish individuals receiving care in their own homes continued to receive AA.

\section{A.3 Summary of all policies}

Table A.1 summarises which allowances were given out to the elderly before and after the policy changes in 2001 and 2002. Since the amounts of allowances differed depending on the care settings, the table separately list the available allowances by where the elderly received care. There are two groups of individuals who benefited from the reforms: i) those receiving nursing care in care homes in all the regions of the UK; ii) the Scottish individuals receiving formal personal care.

In Table A.2, we illustrate how the maximum amounts of weekly allowances changed before and after the reforms depending on where the elderly reside and where they receive care. The 
pre-reform amounts are calculated using the 2000 rates whereas the 2003 rates are employed for the calculations of the post-reform amounts. The table highlights that the changes in the nursing care allowances only applied to those who receive care in residential care homes and the increase experienced by these individuals are comparable across regions. Scottish individuals receiving care at home however saw a large increase in their care allowances due to the 2002 policy reform. This implies two things. Firstly, it is the 2002 Scottish policy to offer free personal care that induced the major care price variation. Secondly, since the majority of individuals receive care in their own homes, the price variation is likely to induce behavioural responses among all Scottish individuals.

Table A.1: Availability of allowances before and after the 2001-2002 reforms

\begin{tabular}{|c|c|c|c|c|}
\hline & \multicolumn{2}{|c|}{ Scotland } & \multicolumn{2}{|c|}{ England, Wales, and Northern Ireland } \\
\hline & At home & Care home & At home & Care home \\
\hline & \multicolumn{4}{|c|}{ Before the 2001-2002 reforms } \\
\hline Nursing care cost covered & Yes & No & Yes & No \\
\hline Personal care allowance & No & No & No & No \\
\hline \multirow[t]{2}{*}{ Attendance allowance } & Yes & Yes & Yes & Yes \\
\hline & \multicolumn{4}{|c|}{ After the 2001-2002 reforms } \\
\hline Nursing care allowance & Yes & Yes & Yes & Yes \\
\hline Personal care allowance & Yes & Yes & No & No \\
\hline Attendance allowance & Yes & No & Yes & Yes \\
\hline
\end{tabular}


Table A.2: Maximum weekly allowance calculations (£ per week)

\begin{tabular}{|c|c|c|}
\hline & Before the reforms (2000 rate) & After the reforms (2003 rate) \\
\hline Care received in care homes & $£$ per week & $£$ per week \\
\hline England & $53.55(\mathrm{AA})$ & $57.20(\mathrm{AA})+142.80(\mathrm{NC})=200.00$ \\
\hline Wales & 53.55 (AA) & $57.20(\mathrm{AA})+119.66(\mathrm{NC})=176.86$ \\
\hline Northern Ireland & 53.55 (AA) & $57.20(\mathrm{AA})+100.00(\mathrm{NC})=157.20$ \\
\hline Scotland & $53.55(\mathrm{AA})$ & $145.00(\mathrm{FPC})+65.00(\mathrm{NC})=210.00$ \\
\hline & Before the reforms (2000 rate) & After the reforms (2003 rate) \\
\hline Care received at home & $£$ per week & $£$ per week \\
\hline England & $53.55(\mathrm{AA})$ & $57.20(\mathrm{AA})$ \\
\hline Wales & $53.55(\mathrm{AA})$ & $57.20(\mathrm{AA})$ \\
\hline Northern Ireland & 53.55 (AA) & $57.20(\mathrm{AA})$ \\
\hline Scotland & $53.55(\mathrm{AA})$ & $57.20(\mathrm{AA})+145(\mathrm{FPC})=202.20$ \\
\hline
\end{tabular}

Notes: This table illustrates how the maximum amounts of weekly allowances changed before and after the reforms depending on where the elderly reside and where they receive care. The pre-reform amounts are calculated using the 2000 rates whereas the 2003 rates are employed for the calculations of the postreform amounts. AA stands for Attendance Allowance; FPC means Formal Personal Care allowance; $\mathrm{NC}$ is the Nursing Care allowance. Since in Scotland the formal personal care allowance for those receiving care at home is not fixed, we use the maximum amount provided to the elderly in residential care homes, i.e. $£ 145$. Note that the nursing care provided in the elderly's home is offered for free at the point of delivery. As a result, nursing care allowance is only given to the elderly receiving care in care homes. In addition, it is worth noting that the attendance allowance is not provided to the Scottish elderly receiving care in care homes after the 2002 reform.

\section{B Further estimation results}

Table B.3: OLS estimation results of Eq. (2) for household wealth with fractional polynomial age functions

\begin{tabular}{|c|c|c|c|}
\hline Variable & Coeff. & & Std. Err. \\
\hline \multicolumn{4}{|l|}{ Fractional polynomial of Age } \\
\hline$\left(\frac{\text { Age-24 }}{10}\right)^{-2}$ & $-14,391.830$ & $* * *$ & $1,809.791$ \\
\hline$\left(\frac{A g e-24}{10}\right)^{-1}$ & $930,060.600$ & $* * *$ & $107,874.000$ \\
\hline$\left(\frac{A g e-24}{10}\right)^{10}-0.5$ & $-5,980,189.000$ & $* * *$ & $660,540.800$ \\
\hline $\ln \left(\frac{A_{g e}^{0}-24}{10}\right)$ & $-3,013,913.000$ & $* * *$ & $315,555.000$ \\
\hline Age-24 & $1,219,975.000$ & $* * *$ & $116,943.900$ \\
\hline$\left(\frac{A g e-24}{10}\right)^{2}$ & $-157,693.600$ & $* * *$ & $14,468.020$ \\
\hline$\left(\frac{A g e-24}{10}\right)^{3}$ & $9,598.399$ & $* * *$ & 856.345 \\
\hline \multicolumn{4}{|c|}{ Fractional polynomial of Age interacted with the indicator for Scotland } \\
\hline$\left(\text { Scotland } * \frac{A g e-24}{10}\right)^{-2}$ & $14,158.120$ & $* * *$ & $1,646.726$ \\
\hline$\left(\text { Scotland } * \frac{A g e-24}{10}\right)^{-1}$ & $-815,031.700$ & $* * *$ & $96,587.720$ \\
\hline$\left(\text { Scotland } * \frac{A g e-24}{10}\right)^{-0.5}$ & $4,805,877.000$ & $* * *$ & $585,883.600$ \\
\hline Scotland $* \ln \left(\frac{A g e-24}{10}\right)$ & $2,179,596.000$ & $* * *$ & $276,973.100$ \\
\hline Scotland $* \frac{A g e-24}{10}$ & $-708,643.800$ & $* * *$ & $101,139.500$ \\
\hline$\left(\text { Scotland } * \frac{A g e-24}{10}\right)^{2}$ & $78,872.830$ & $* * *$ & $12,751.910$ \\
\hline$\left(\text { Scotland } * \frac{A g e-24}{10}\right)^{3}$ & $-4,327.233$ & $* * *$ & 776.527 \\
\hline \multicolumn{4}{|c|}{ Fractional polynomial of Age interacted with the indicator for after the reform } \\
\hline$\left(\text { After } * \frac{A g e-24}{10}\right)^{-2}$ & $-11,401.610$ & $* * *$ & $2,269.573$ \\
\hline$\left(\text { After } * \frac{A g e-24}{10}\right)^{-1}$ & $663,700.500$ & $* * *$ & $123,643.300$ \\
\hline$\left(\text { After } \frac{A g e-24}{10}\right)^{-0.5}$ & $-3,992,694.000$ & $* * *$ & $713,199.100$ \\
\hline After $* \ln \left(\frac{10 g e-24}{10}\right)$ & $-1,868,979.000$ & $* * *$ & $319,007.000$ \\
\hline
\end{tabular}


Table B.3 - continued from previous page

\begin{tabular}{|c|c|c|c|}
\hline Variable & Coeff. & & Std. Err. \\
\hline After $* \frac{A g e-24}{10}$ & $665,245.900$ & $* * *$ & $103,003.500$ \\
\hline$\left(\text { After } * \frac{A_{g e}^{10}-24}{10}\right)^{2}$ & $-81,460.660$ & $* * *$ & $11,674.720$ \\
\hline$\left(\text { After } * \frac{A g e-24}{10}\right)^{3}$ & $4,812.909$ & $* * *$ & 671.032 \\
\hline \multicolumn{4}{|c|}{ Fractional polynomial of Age interacted with the indicators for Scotland and for after the reform } \\
\hline$\left(\text { After } * \text { Scotland } * \frac{\text { Age }-24}{10}\right)^{-2}$ & $-5,201.085$ & $*$ & $2,346.753$ \\
\hline$\left(\text { After } * \text { Scotland } * \frac{A g e-24}{10}\right)^{-1}$ & $254,863.900$ & * & $127,529.100$ \\
\hline$\left(\text { After } * \text { Scotland } * \frac{A g e-24}{10}\right)^{-0.5}$ & $-1,276,496.000$ & & $735,336.300$ \\
\hline After $*$ Scotland $* \ln \left(\frac{A g e-24}{10}\right)$ & $-436,716.200$ & & $329,226.300$ \\
\hline After $*$ Scotland $* \frac{A g e-24}{10}$ & $11,426.610$ & & $107,112.700$ \\
\hline$\left(\text { After } * \text { Scotland } * \frac{A g e-24}{10}\right)^{2}$ & $13,701.520$ & & $12,276.690$ \\
\hline$\left(\text { After } * \text { Scotland } * \frac{A g e-24}{10}\right)^{3}$ & $-1,427.599$ & * & 712.423 \\
\hline After $*$ Scotland & $1,001,713.000$ & $*$ & $519,197.000$ \\
\hline Female & $-1,217.683$ & * & 656.356 \\
\hline Non-white & $-19,409.230$ & $* * *$ & $3,245.656$ \\
\hline \multicolumn{4}{|l|}{ Region of residence-Reference: North-East } \\
\hline North West and Merseyside & $-2,315.686$ & & $1,497.922$ \\
\hline Yorkshire and the Humber & $-3,193.867$ & ** & $1,407.313$ \\
\hline East Midlands & $-3,489.708$ & & $2,733.595$ \\
\hline West Midlands & $7,390.526$ & $* * *$ & $1,669.605$ \\
\hline Eastern & $-10,322.510$ & & $8,725.897$ \\
\hline London & $10,886.200$ & & $12,207.330$ \\
\hline South East & $-4,881.994$ & & $9,538.448$ \\
\hline South West & $-3,274.339$ & & $5,897.353$ \\
\hline Wales & $-4,575.994$ & & $2,753.281$ \\
\hline Scotland & $-3,377,898.000$ & $* * *$ & $404,369.700$ \\
\hline \multicolumn{4}{|l|}{ Civil status - Reference: Divorced } \\
\hline Married & $13,544.340$ & $* * *$ & $3,238.950$ \\
\hline Couple & $15,877.740$ & $* * *$ & $1,965.480$ \\
\hline Single & $6,507.958$ & $* * *$ & $1,592.814$ \\
\hline Widowed & $8,007.573$ & $* * *$ & 941.662 \\
\hline Separated & $1,951.790$ & & $1,476.234$ \\
\hline \multicolumn{4}{|l|}{ Education-Reference: edu 7} \\
\hline $0-12$ & $-6,242.434$ & $*$ & $3,017.524$ \\
\hline $13-15$ & $-12,172.490$ & $* * *$ & $1,459.157$ \\
\hline $16-18$ & $7,959.880$ & $* * *$ & $2,289.946$ \\
\hline $19-21$ & $19,803.440$ & $* * *$ & $2,084.035$ \\
\hline $22-23$ & $20,583.020$ & $* * *$ & $2,654.466$ \\
\hline $24-27$ & $15,126.550$ & $* * *$ & $2,239.992$ \\
\hline \multicolumn{4}{|l|}{ Education of the spouse - Reference: Single } \\
\hline $0-12$ & $1,559.072$ & & $1,863.947$ \\
\hline $13-15$ & $10,691.860$ & ** & $4,514.391$ \\
\hline $16-18$ & $25,083.060$ & $* * *$ & $6,449.143$ \\
\hline $19-21$ & $33,182.170$ & $* * *$ & $6,947.018$ \\
\hline $22-23$ & $30,385.230$ & $* * *$ & $7,004.361$ \\
\hline $24-27$ & $23,317.160$ & $* * *$ & $5,160.160$ \\
\hline 28 and above & $15,150.050$ & ** & $5,187.257$ \\
\hline Presence of kids $<5$ years & $-4,471.349$ & $* * *$ & 461.849 \\
\hline Presence of kids $[5,11)$ years & $-1,282.698$ & ** & 432.340 \\
\hline Presence of kids $[11,15)$ years & -810.124 & & 503.016 \\
\hline Regional unemployment rate by gender & $-2,042.772$ & $* * *$ & 427.980 \\
\hline Per capita regional gross value added & -3.648 & & 2.047 \\
\hline Per capita regional gross disposable income & 18.595 & $* * *$ & 5.140 \\
\hline Variation of per capita regional gross value added & 3.478 & & 2.370 \\
\hline Variation of per capita regional gross disposable income & -19.962 & $* * *$ & 4.320 \\
\hline \multicolumn{4}{|l|}{ Wave dummies - Reference: 1999} \\
\hline 2000 & -521.133 & & $2,295.587$ \\
\hline
\end{tabular}


Table B.3 - continued from previous page

\begin{tabular}{|c|c|c|c|}
\hline Variable & Coeff. & & Std. Err. \\
\hline 2001 & $-3,004.441$ & & $3,643.731$ \\
\hline 2002 & $2,747,688.000$ & $* * *$ & $503,436.100$ \\
\hline 2003 & $2,747,723.000$ & $* * *$ & $503,471.600$ \\
\hline 2004 & $2,748,916.000$ & $* * *$ & $503,604.200$ \\
\hline 2005 & $2,749,745.000$ & $* * *$ & $503,749.500$ \\
\hline 2006 & $2,746,289.000$ & $* * *$ & $502,657.200$ \\
\hline 2007 & $2,745,235.000$ & $* * *$ & $503,055.700$ \\
\hline Constant & $3,860,123.000$ & $* * *$ & $451,196.700$ \\
\hline Observations & \multicolumn{3}{|c|}{158,562} \\
\hline$R^{2}$ & \multicolumn{3}{|c|}{0.267} \\
\hline \# of clusters & \multirow{2}{*}{\multicolumn{3}{|c|}{11}} \\
\hline \# of parameters & \multicolumn{2}{|r|}{76} & \\
\hline
\end{tabular}


Table B.4: OLS estimation results of Eq. (2) for household wealth with piecewise constant age functions

\begin{tabular}{|c|c|c|c|}
\hline Variable & Coeff. & & Std. Err. \\
\hline \multicolumn{4}{|c|}{ Piecewise constant function of Age } \\
\hline Age $27-28$ & $-3,640.623$ & $*$ & $1,720.614$ \\
\hline Age $29-30$ & $-2,309.379$ & & $2,466.854$ \\
\hline Age $31-32$ & $-3,359.471$ & & $2,676.150$ \\
\hline Age $33-34$ & -837.512 & & $2,016.416$ \\
\hline Age $35-36$ & $2,603.437$ & & $3,077.579$ \\
\hline Age $37-38$ & $6,411.099$ & & $3,861.718$ \\
\hline Age $39-40$ & $8,560.623$ & $* *$ & $3,260.868$ \\
\hline Age $41-42$ & $13,578.980$ & $* * *$ & $3,719.202$ \\
\hline Age $43-44$ & $19,701.660$ & $* * *$ & $3,561.395$ \\
\hline Age $45-46$ & $24,266.020$ & $* * *$ & $4,612.231$ \\
\hline Age $47-48$ & $26,897.230$ & $* * *$ & $4,341.602$ \\
\hline Age $49-50$ & $30,499.330$ & $* * *$ & $5,482.590$ \\
\hline Age $51-52$ & $34,709.610$ & $* * *$ & $4,872.904$ \\
\hline Age $53-54$ & $39,112.780$ & $* * *$ & $5,296.381$ \\
\hline Age $55-56$ & $39,971.820$ & $* * *$ & $5,957.581$ \\
\hline Age $57-58$ & $37,668.320$ & $* * *$ & $5,999.068$ \\
\hline Age $59-60$ & $34,671.380$ & $* * *$ & $6,045.994$ \\
\hline Age $61-62$ & $29,637.000$ & $* * *$ & $4,440.718$ \\
\hline Age $63-64$ & $25,580.820$ & $* * *$ & $4,004.023$ \\
\hline Age $65-66$ & $19,405.520$ & $* * *$ & $4,101.178$ \\
\hline Age $67-68$ & $18,007.140$ & $* * *$ & $2,556.863$ \\
\hline Age $69-70$ & $15,313.650$ & $* * *$ & $3,136.033$ \\
\hline Age $71-72$ & $9,737.075$ & $* * *$ & $2,192.641$ \\
\hline Age $73-74$ & $10,781.570$ & $* * *$ & $2,841.316$ \\
\hline Age $75-76$ & $10,444.820$ & $* * *$ & $3,175.507$ \\
\hline Age $77-78$ & $10,708.400$ & $* * *$ & $3,015.547$ \\
\hline Age 79 or more & $9,677.167$ & $* * *$ & $2,394.064$ \\
\hline \multicolumn{4}{|c|}{ Piecewise constant function of Age interacted with the indicator for Scotland } \\
\hline Scotland*Age $25-26$ & -598.565 & & $4,423.656$ \\
\hline Scotland*Age $27-28$ & $2,562.544$ & & $3,470.183$ \\
\hline Scotland*Age $29-30$ & -316.993 & & $2,445.866$ \\
\hline Scotland*Age 31-32 & -184.039 & & $2,588.938$ \\
\hline Scotland*Age $33-34$ & $-19,083.820$ & $* * *$ & $2,451.433$ \\
\hline Scotland*Age $35-36$ & $-5,820.075$ & $* * *$ & $1,774.331$ \\
\hline Scotland*Age $37-38$ & $-5,367.710$ & $* *$ & $2,024.217$ \\
\hline Scotland*Age 39-40 & $-7,927.541$ & $* * *$ & $2,247.638$ \\
\hline Scotland*Age 41-42 & $-9,399.943$ & $* * *$ & $2,563.934$ \\
\hline Scotland*Age 43-44 & $-2,028.518$ & & $2,994.110$ \\
\hline Scotland*Age 45-46 & $-10,157.430$ & $* *$ & $3,421.222$ \\
\hline Scotland*Age $47-48$ & $-10,565.290$ & $* * *$ & $2,215.133$ \\
\hline Scotland*Age 49-50 & $-12,069.400$ & $* * *$ & $3,101.593$ \\
\hline Scotland*Age 51-52 & $-7,701.986$ & $* *$ & $2,589.500$ \\
\hline Scotland*Age 53-54 & $-17,842.000$ & $* * *$ & $4,433.263$ \\
\hline Scotland*Age 55-56 & $-15,844.700$ & $* * *$ & $3,838.236$ \\
\hline Scotland*Age $57-58$ & $-12,310.600$ & $* * *$ & $2,757.393$ \\
\hline Scotland*Age 59-60 & $-12,060.230$ & $* * *$ & $3,696.155$ \\
\hline Scotland*Age 61-62 & $-4,208.390$ & & $2,538.703$ \\
\hline Scotland*Age 63-64 & $-4,520.179$ & & $3,731.333$ \\
\hline Scotland*Age 65-66 & $-2,592.015$ & & $3,804.262$ \\
\hline Scotland*Age 67-68 & $-2,109.346$ & & $4,208.216$ \\
\hline Scotland*Age $69-70$ & -830.613 & & $4,020.981$ \\
\hline Scotland*Age 71-72 & $6,916.727$ & & $4,831.345$ \\
\hline Scotland*Age 73-74 & $3,840.592$ & & $3,323.444$ \\
\hline Scotland*Age $75-76$ & $3,356.564$ & & $3,374.606$ \\
\hline
\end{tabular}


Table B.4 - continued from previous page

\begin{tabular}{|c|c|c|c|}
\hline Variable & Coeff. & & Std. Err. \\
\hline Scotland*Age 77-78 & $7,995.874$ & * & $4,221.777$ \\
\hline Scotland*Age 79 or more & $7,309.020$ & & $4,544.470$ \\
\hline \multicolumn{4}{|c|}{ Piecewise constant function of Age interacted with the indicator for for after the reform } \\
\hline After*Age $27-28$ & 65.410 & & $2,028.411$ \\
\hline After*Age $29-30$ & $1,408.028$ & & $2,053.765$ \\
\hline After*Age 31-32 & $6,086.911$ & **** & $1,580.467$ \\
\hline After*Age 33-34 & $6,883.073$ & $* * *$ & 922.738 \\
\hline After*Age $35-36$ & $7,636.009$ & $* * *$ & $1,432.145$ \\
\hline After*Age $37-38$ & $8,576.158$ & *** & $2,294.367$ \\
\hline After*Age $39-40$ & $12,482.600$ & $* * *$ & $1,927.954$ \\
\hline After*Age 41-42 & $10,660.790$ & $* * *$ & $1,209.716$ \\
\hline After*Age $43-44$ & $9,726.199$ & $* * *$ & $1,744.860$ \\
\hline After*Age $45-46$ & $10,277.550$ & $* * *$ & $1,220.195$ \\
\hline After*Age $47-48$ & $13,093.070$ & $* * *$ & $2,528.113$ \\
\hline After*Age 49-50 & $15,785.560$ & $* * *$ & $1,690.963$ \\
\hline After*Age 51-52 & $12,565.060$ & $* * *$ & $3,180.123$ \\
\hline After*Age 53-54 & $12,102.230$ & $* * *$ & $2,764.989$ \\
\hline After*Age 55-56 & $11,650.010$ & $* * *$ & $1,797.717$ \\
\hline After*Age 57-58 & $14,669.610$ & $* * *$ & $2,996.603$ \\
\hline After*Age 59-60 & $10,108.380$ & $* * *$ & $2,138.700$ \\
\hline After*Age 61-62 & $7,504.087$ & $* *$ & $3,213.293$ \\
\hline After*Age 63-64 & $1,558.052$ & & $1,588.365$ \\
\hline After*Age $65-66$ & $-4,324.268$ & $*$ & $2,350.868$ \\
\hline After*Age 67-68 & $-7,566.763$ & $* * *$ & $1,953.870$ \\
\hline After*Age $69-70$ & $-5,451.462$ & $* *$ & $2,381.494$ \\
\hline After*Age 71-72 & $-8,879.948$ & $* *$ & $3,261.729$ \\
\hline After*Age 73-74 & $-8,647.065$ & $* * *$ & $2,693.367$ \\
\hline After*Age 75-76 & $-14,238.710$ & $* * *$ & $1,938.496$ \\
\hline After*Age $77-78$ & $-12,806.370$ & $* * *$ & $2,630.071$ \\
\hline After*Age 79 or more & $-13,648.530$ & $* * *$ & $1,003.646$ \\
\hline \multicolumn{4}{|c|}{ Piecewise constant function of Age interacted with the indicators for Scotland and for after the reform } \\
\hline Scotland*Age $25-26$ & $-1,350.268$ & & $1,654.364$ \\
\hline Scotland*Age 27-28 & $-3,711.942$ & & $2,200.660$ \\
\hline Scotland*Age 29-30 & $-3,110.856$ & & $2,472.844$ \\
\hline Scotland*Age 31-32 & $-6,057.488$ & ** & $2,175.678$ \\
\hline Scotland*Age 33-34 & $9,921.842$ & $* * *$ & $1,354.543$ \\
\hline Scotland*Age 35-36 & $-3,913.735$ & ** & $1,332.962$ \\
\hline Scotland*Age 37-38 & $-7,104.679$ & ** & $2,339.327$ \\
\hline Scotland*Age 39-40 & $-9,824.099$ & $* * *$ & $2,105.927$ \\
\hline Scotland*Age 41-42 & $-7,033.708$ & $* * *$ & $2,105.137$ \\
\hline Scotland*Age 43-44 & $-16,826.840$ & $* * *$ & $2,284.923$ \\
\hline Scotland*Age 45-46 & $-9,863.178$ & $* * *$ & $1,490.349$ \\
\hline Scotland*Age 47-48 & $-11,731.500$ & $* * *$ & $2,892.984$ \\
\hline Scotland*Age 49-50 & $-11,812.210$ & $* * *$ & $1,962.619$ \\
\hline Scotland*Age 51-52 & $-15,441.440$ & $* * *$ & $2,727.069$ \\
\hline Scotland*Age 53-54 & $-5,840.291$ & $* *$ & $2,127.048$ \\
\hline Scotland*Age 55-56 & $-8,362.013$ & $* * *$ & $1,499.238$ \\
\hline Scotland*Age 57-58 & $-12,412.180$ & $* * *$ & $2,654.594$ \\
\hline Scotland*Age 59-60 & $-9,394.938$ & $* * *$ & $2,224.463$ \\
\hline Scotland*Age 61-62 & $-9,864.714$ & $* *$ & $3,202.895$ \\
\hline Scotland*Age 63-64 & $-6,991.072$ & $* * *$ & $1,284.364$ \\
\hline Scotland*Age 65-66 & 248.599 & & $2,799.279$ \\
\hline Scotland*Age 67-68 & 639.993 & & $1,767.656$ \\
\hline Scotland*Age 69-70 & $-2,762.828$ & & $3,121.546$ \\
\hline Scotland*Age 71-72 & $-2,514.614$ & & $3,082.075$ \\
\hline Scotland*Age 73-74 & $2,346.693$ & & $2,380.556$ \\
\hline \multirow[t]{2}{*}{ Scotland*Age 75-76 } & $1,846.814$ & & $1,674.259$ \\
\hline & \multicolumn{3}{|c|}{ Continued on next page } \\
\hline
\end{tabular}


Table B.4 - continued from previous page

\begin{tabular}{|c|c|c|c|}
\hline Variable & Coeff. & & Std. Err. \\
\hline Scotland*Age 77-78 & $-4,608.543$ & ** & $1,590.241$ \\
\hline Scotland*Age 79 or more & $-1,368.487$ & & $1,511.510$ \\
\hline Female & $-1,223.714$ & $*$ & 656.170 \\
\hline Non-white & $-19,334.660$ & $* * *$ & $3,219.229$ \\
\hline \multicolumn{4}{|l|}{ Region of residence-Reference: North-East } \\
\hline North West and Merseyside & $-2,384.082$ & & $1,515.982$ \\
\hline Yorkshire and the Humber & $-3,238.604$ & ** & $1,430.937$ \\
\hline East Midlands & $-3,569.108$ & & $2,757.149$ \\
\hline West Midlands & $7,322.136$ & $* * *$ & $1,669.790$ \\
\hline Eastern & $-10,529.940$ & & $8,755.342$ \\
\hline London & $10,844.400$ & & $12,112.490$ \\
\hline South East & $-5,083.357$ & & $9,582.496$ \\
\hline South West & $-3,420.024$ & & $5,930.897$ \\
\hline Wales & $-4,631.413$ & & $2,755.588$ \\
\hline \multicolumn{4}{|l|}{ Civil status - Reference: Divorced } \\
\hline Married & $13,453.090$ & $* * *$ & $3,284.651$ \\
\hline Couple & $15,774.340$ & $* * *$ & $1,951.999$ \\
\hline Single & $6,445.221$ & $* * *$ & $1,587.139$ \\
\hline Widowed & $8,014.914$ & $* * *$ & 970.426 \\
\hline Separated & $1,922.860$ & & $1,493.557$ \\
\hline \multicolumn{4}{|l|}{ Education-Reference: edu7 } \\
\hline $0-12$ & $-6,274.213$ & $*$ & $3,049.961$ \\
\hline $13-15$ & $-12,438.570$ & $* * *$ & $1,449.516$ \\
\hline $16-18$ & $7,813.867$ & $* * *$ & $2,277.168$ \\
\hline $19-21$ & $19,611.370$ & $* * *$ & $2,059.255$ \\
\hline $22-23$ & $20,400.890$ & $* * *$ & $2,637.866$ \\
\hline $24-27$ & $14,857.240$ & $* * *$ & $2,198.641$ \\
\hline \multicolumn{4}{|l|}{ Education of the spouse - Reference: Single } \\
\hline $0-12$ & $1,538.354$ & & $1,923.138$ \\
\hline $13-15$ & $10,585.710$ & ** & $4,544.811$ \\
\hline $16-18$ & $25,107.180$ & $* * *$ & $6,481.889$ \\
\hline $19-21$ & $33,188.570$ & $* * *$ & $6,968.239$ \\
\hline $22-23$ & $30,432.280$ & $* * *$ & $7,020.768$ \\
\hline $24-27$ & $23,242.640$ & $* * *$ & $5,182.132$ \\
\hline 28 and above & $15,506.690$ & $* *$ & $5,174.090$ \\
\hline Presence of kids $<5$ years & $-4,631.886$ & $* * *$ & 467.053 \\
\hline Presence of kids $[5,11)$ years & $-1,384.616$ & $* * *$ & 426.412 \\
\hline Presence of kids $[11,15)$ years & -566.212 & & 456.955 \\
\hline Regional unemployment rate by gender & $-2,035.377$ & $* * *$ & 428.609 \\
\hline Per capita regional gross value added & -3.676 & * & 2.031 \\
\hline Per capita regional gross disposable income & 18.685 & $* * *$ & 5.125 \\
\hline Variation of per capita regional gross value added & 3.541 & & 2.334 \\
\hline Variation of per capita regional gross disposable income & -20.105 & $* * *$ & 4.331 \\
\hline \multicolumn{4}{|l|}{ Wave dummies - Reference: 1999} \\
\hline 2000 & -518.019 & & $2,272.633$ \\
\hline 2001 & $-3,073.781$ & & $3,618.127$ \\
\hline 2002 & $-11,192.310$ & $*$ & $5,806.940$ \\
\hline 2003 & $-11,240.230$ & & $6,676.421$ \\
\hline 2004 & $-9,998.618$ & & $7,503.655$ \\
\hline 2005 & $-9,186.138$ & & $8,490.123$ \\
\hline 2006 & $-12,639.010$ & & $8,937.803$ \\
\hline 2007 & $-13,668.400$ & & $10,134.400$ \\
\hline Constant & $-131,812.200$ & $* * *$ & $27,626.500$ \\
\hline Observations & \multicolumn{3}{|c|}{158,562} \\
\hline$R^{2}$ & \multicolumn{3}{|c|}{0.268} \\
\hline \# of clusters & \multirow{2}{*}{\multicolumn{3}{|c|}{$\begin{array}{c}11 \\
156\end{array}$}} \\
\hline \# of parameters & & & \\
\hline
\end{tabular}

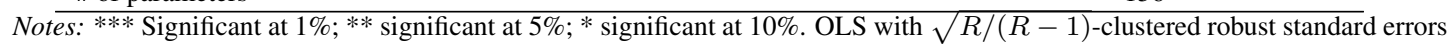
and $t_{R-1}$ critical values as suggested in Brewer et al. (2013). 